\title{
PRICE LIMITS IN A TRADABLE PERFORMANCE STANDARD
}

\author{
Banban Wang \\ William A. Pizer \\ Clayton Munnings \\ Working Paper 28368 \\ http://www.nber.org/papers/w28368
NATIONAL BUREAU OF ECONOMIC RESEARCH
1050 Massachusetts Avenue
Cambridge, MA 02138
January 2021

The authors wish to thank Xiaochen Sun for excellent research assistance. We also received valuable comments from seminar participants at the Duke University Energy Initiative, HUST, and Tsinghua University. The views expressed herein are those of the authors and do not necessarily reflect the views of the National Bureau of Economic Research.

NBER working papers are circulated for discussion and comment purposes. They have not been peer-reviewed or been subject to the review by the NBER Board of Directors that accompanies official NBER publications.

(C) 2021 by Banban Wang, William A. Pizer, and Clayton Munnings. All rights reserved. Short sections of text, not to exceed two paragraphs, may be quoted without explicit permission provided that full credit, including ( $)$ notice, is given to the source. 
Price Limits in a Tradable Performance Standard

Banban Wang, William A. Pizer, and Clayton Munnings

NBER Working Paper No. 28368

January 2021

JEL No. D82,Q54,Q58

\begin{abstract}
$\underline{\text { ABSTRACT }}$
Tradable performance standards are widely used sectoral regulatory policies. Examples include the US lead phasedown, fuel economy standards for automobiles, renewable portfolio standards, low carbon fuel standards, and-most recently-China's new national carbon market. At the same time, theory and experience with traditional cap-and-trade programs suggests an important role for price limits in the form of floors, ceilings, and reserves. In this paper we develop a simple analytical model to derive the welfare comparison between tradable performance standards and a price-based alternative. This works out to be is a simple variant of the traditional Weitzman prices-versus-quantities result. We use this result to show that substantial gains could arise from shifting two programs, China's new national carbon market ( $\sim 60 \%$ gain) and the California Low Carbon Fuel Standard ( $\sim 20 \%$ gain), to a price mechanism. This will generally be true when the coefficient of variation in the price under a TPS is larger than $50 \%$. We end with a discussion of implementation issues, including full and partial consignment auctions based on actual and expected output.
\end{abstract}

\author{
Banban Wang \\ School of Economics \\ Huazhong University of Science \\ and Technology \\ 1037 Luoyu Road \\ Hongshan District \\ Wuhan, Hubei 430074 \\ China \\ wangbanban@hust.edu.cn \\ William A. Pizer \\ Sanford School of Public Policy \\ Duke University \\ Box 90312 \\ Durham, NC 27708 \\ and NBER \\ billy.pizer@duke.edu
}

Clayton Munnings

Energy and Resources Group

University of California Berkeley

310 Barrows Hall

Berkeley, California, 94720

cminfocus@gmail.com 


\section{Introduction}

Tradable performance standards (TPS) are a popular form of sectoral market-based regulation that require regulated polluters to meet an emission-per-unit-of-output performance standard on average across the sector. Regulated polluters earn emission permits, denoted in tons of emissions, based on their level of output multiplied by the performance standard, while acquiring obligations based on their actual emissions. When their emissions rate is below the standard they end up with a surplus and when their emissions rate exceeds the standard they end up with a deficit. Those with a surplus can sell to those with a deficit (trading) or hold them for use in the future (banking). TPSs can be conceptualized as a rate-based version of a "mass"-based emissions trading systems (ETS). That is, under an ETS the aggregate mass of emissions is fixed; under a TPS the aggregate emission rate (emissions per output) is fixed. There are many examples of TPSs including the US lead phasedown, fuel economy standards for automobiles, renewable portfolio standards, low carbon fuel standards, and China's new national carbon market (Newell and Rogers 2003; Farrell and Sperling 2007; Pizer and Zhang 2018; Goulder et al. 2019; Yeh et al. 2020). Most recently, legislative proposals in the US Congress and President Biden's climate plan feature a TPS for the power sector.

Despite the prevalence of TPSs, most of the economic literature focuses on the design of ETSs. An important conclusion in that literature is that managing permit prices (either by enforcing minimum or maximum prices) increases welfare and other benefits by reducing expected compliance costs for regulated polluters (Pizer 2002; Murray, Newell, and Pizer 2009; Burtraw, Palmer, and Kahn 2010; Newell, Pizer, and Zhang 2005; Wood and Jotzo 2011; Roberts and Spence 1976). However, this idea has been rarely discussed in the context of a TPS.

We address this gap in the literature by considering price limits in the context of a TPS, resulting in a hybrid TPS. We first develop a simple analytical model to compare the welfare between a TPS and a comparable price-based alternative, the feebate. A feebate can be viewed as a tax on emissions coupled with a revenue neutral rebate on outputessentially fixing the emission price rather than the emissions rate. ${ }^{1}$ Focusing on sectoral level policy, we modify the traditional Weitzman (1974) prices-versus-quantities framework by adopting an alternative unit cost function.. We find that with unit cost shocks, the Weitzman's comparative advantage expression continues to hold with a minor adjustment to the marginal benefit slope. In particular, the slope of the marginal benefit schedule increases based on the coefficient of variation in output.

We apply our simple comparative expression to two current TPSs, the new Chinese national carbon market and California's Low Carbon Fuel Standard (LCFS). Using recent cost estimates for both programs along with other data to calibrate the parameters, we estimate large welfare advantages from using a feebate rather than using a TPS. These

1 We discuss and compare a TPS and feebate in Appendix A. 
relative gains are on the order of 60 percent for the Chinese program and 20 percent in the California program based on central cases. The more general result is that this relative gain will be large when the coefficient of variation in under the TPS is large (for example, greater than one-half).

Finally, we discuss practical issues regarding the implementation of a price floor in the context of our hybrid TPS. We the first introduce the idea of a consignment auction with a minimum reserve price that mimics a feebate when the market price reaches the reserve price. We then consider additional issues including full or partial consignment, treatment of unsold permits, and advanced allocation of permits.

The widespread and growing use of sectoral TPSs coupled with the demonstrated advantages of price limits in ETSs motivate this paper. The first large-scale TPS, the US lead phasedown, required refineries to decrease the average lead content of all gasoline to 10 percent of its original level (lead/gallon). A trading program related to the standard was launched in 1982 to allow inter-refinery trading. In 1987, by the time the system terminated, the phasedown successfully met the target and was considered highly cost-effective (Newell and Rogers 2003; Schmalensee and Stavins 2017).

In another example, the early US Corporate Average Fuel Economy (CAFE) standards were updated to allow permit trading in 2012. This program can be thought of as regulating the lifetime greenhouse gas emissions per car sold, assuming every car is driven the same number of miles over its lifetime. The accounting is complicated, but effectively allows for trading and banking of permits. The program also includes a maximum price in the form of a per unit compliance penalty when a manufacturer knowingly or unknowingly exceeds the standard (Klier and Linn 2011; Leard and McConnell 2017).

In the power sector, renewable portfolio standards are a widely used example of TPSs. They set obligations on electricity sellers to acquire a certain proportion of their electricity from renewable energy (denoted as renewable kilowatt-hours as a share of total kilowatt-hours sold). Tradable permits (referred to as Renewable Energy Certificates in the United States or Green Certificates in the European Union) are then generated from eligible renewable energy sources and used for compliance. Such trading programs have been implemented widely in around half of the United States as well as in the United Kingdom and several other European countries (Barbose 2019). Some of these programs include an alternative compliance payment that functions as a maximum price.

The California low carbon fuel standard and China's new national carbon market are two recent TPS examples that we discuss at length later in the paper as numerical applications of our theoretical results. On the horizon, several policy proposals in the United States have featured a clean energy standard, which require a certain percentage of retail electricity sales comes from zero or low emitting sources. For example, H.R. 7516 would transition the United States electric sector to one hundred percent clean energy by 2050 (DeGette 2020). Even more ambitiously, President Biden's climate plan features a clean energy standard that achieves carbon-pollution free energy in electricity generation by 2035 (Biden 2020). 
It is worth noting that with the exception of fuel economy standards, we are unaware of any work comparing sectoral TPSs to feebates. Nor has there been any discussion of how a price floor might be implemented in conjunction with a TPS, despite the importance of price floors in ETSs. This paper aims to contribute in both regards.

The remainder of this paper is organized as follows. Section 2 reviews the existing literature comparing price and quantity market-based policies in the context of rate-based instruments (e.g., feebates and TPSs). Section 3 develops our model and derives the comparative advantage expression for feebates versus TPSs. Section 4 estimates welfare gains earned by switching from a TPS to a feebate in the context of California's low carbon fuel standard and China's new carbon trading program. Section 5 presents consignment auctions as a way to integrate price floors into a TPS and discusses associated design choices. Section 6 concludes.

\section{Literature Review}

There is a considerable volume of theoretical work comparing price-based taxes and quantity-based policies such as ETSs. This begins with Weitzman's (1974) seminal result that price-based instruments have higher expected net benefits than quantity-based instruments when marginal benefits are flatter than marginal costs and marginal costs are uncertain. This basic finding has been extended widely by considering alternative versions of uncertainty, different cost and benefit functions, and with applications to stock pollutants and dynamic settings (Fishelson 1976; Stavins 1996; Yohe 1978; Hoel and Karp 2002; Newell and Pizer 2003; Weitzman 2018; Pizer and Prest 2020).

As most pollution externalities have relatively flat benefits, price instruments tend to outperform quantity instruments (Pizer 2002). Therefore, ETSs can enhance their welfare by imposing price controls. Such a policy represents a hybrid price-quantity system first proposed by Roberts and Spence (1976). They model an ETS with minimum and maximum prices, showing that by nesting strict price and quantity controls as special cases, the hybrid policy offers an improvement. Pizer (2002) elaborates on the implementation of price controls, articulating the idea of a "safety valve" whereby a regulator sells an unlimited number of additional permits at a specified trigger price.

Burtraw et al. (2010) combine the safety valve, fixing a maximum price, with a reserve-price permit auction to enforce a minimum price. This symmetric price corridor protects against potential price spikes as well as potential price lulls. Murray et al. (2009) elaborate further upon the implementation of a maximum price, proposing an allowance reserve mechanism. Rather than selling an unlimited number of additional allowances at a single trigger price, multiple fixed-volume tranches of permits can be introduced via auction at multiple trigger prices. In addition to the expected welfare benefits from hybrid mechanisms, Grüll and Taschini (2011) discuss additional economic advantages for regulated polluters. 
Beyond economic considerations, price controls in an ETS can lead to stronger stakeholder support. Typically, environmental advocates support the addition of a minimum price to an ETS to achieve higher levels of ambition. Meanwhile, business interests favor the introduction of a maximum price to an ETS to protect against excessive compliance costs (Aldy 2017). In recent years, as most ETSs have experienced relatively low prices, calls for price minimums have increased (Wood and Jotzo 2011). For example, the European Union Emissions Trading Scheme (EU ETS) has suffered from low allowances prices since the 2009 economic crisis. They recently completed structural reforms that have significantly increased allowance prices. Partly based on the early experiences in the EU ETS, many ETSs - including the Regional Greenhouse Gas Initiative and the California cap and trade program in the United States - chose to set price minimums via reserve prices at allowance auctions (Hepburn et al. 2016; Schmalensee and Stavins 2017). In practice, price controls for ETSs have been important for policy performance and political durability.

Price controls applied to a TPS have received less attention in the literature compared to price controls applied to an ETS. Moreover, TPSs generally have received less attention than ETSs. One line of work has focused on the choice between a TPS and ETS (Fischer 2003; Fischer and Springborn 2011; Zhang, Chen, and Tanaka 2018; Ellerman and Wing 2003; Kolstad 2005; Jotzo and Pezzey 2007a; Marschinski and Edenhofer 2010a; Webster, Sue Wing, and Jakobovits 2010; Lemoine 2017). Davis and Knittel (2018) compare a TPS to a non-tradable performance standard with special attention to distributional effects. Other papers consider the effect of market power, productivity, dynamic contexts, and other sector-based features on TPS outcomes (Rubin, Leiby, and Greene 2009; Tombe and Winter 2015; Becker 2020).

The price-based alternative to a TPS, a feebate, has been largely discussed as an alternative to fuel economy standards for motor vehicles (D. L. Greene 1990; D. L. Greene et al. 2005; Johnson 2006; Dumas, Greene, and Bourbeau 2007; Bunch et al. 2011; Adamou, Clerides, and Zachariadis 2014; Durrmeyer 2018). Bernard et al (2007) focus on whether a rebate is really necessary in the feebate. Other studies provide an empirical evaluation of feebates in different countries (D'Haultfœuille, Givord, and Boutin 2014; Konishi and Zhao 2017; Yan and Eskeland 2018).

A few papers do compare taxes or feebates to a TPS. For example, Gillingham (2013) use a numerical simulation to find that welfare is similar for a TPS or feebate when applied to US fuel economy standards, and argues that the final welfare effect is dependent on implementation. Durrmeyer and Samano (2018) simulate non-tradable fuel economy standards and the feebate policies in France and the US, finding that feebates have smaller negative welfare effects. Caparros et al (2016) compare pollution taxes to equipment standards, both varying over time and set to achieve a fixed emission outcome. Holland (2012) compares TPS and taxes when there is leakage. None of these four papers model focus on welfare outcomes when there is cost and output uncertainty, as we do in this paper. Kellogg (2018) is the one paper in this literature that develops and applies a 
comparative advantage expression for a TPS versus feebate like ours. Moreover, he concludes that more price volatility under a TPS reduces its welfare improvement. This is analogous to our conclusion that the welfare gain from a feebate is largest when the coefficient of variation in prices under a TPS is large. Our paper seeks to generalize his work in a number of ways, including abstracting from the fuel-economy application and allowing both quadratic (rather than linear) benefits as well as correlation between output and cost uncertainty. We note that Kellogg (2020) uses a similar model but focused on the TPS versus ETS question (or another type of indexed emission limit).

Quirion (2005), Newell and Pizer (2008), Branger and Quirion (2014) and Zhao (2018) are similar in spirit to our paper. They focus on deriving general policy comparisons, including TPSs and feebates, though they focus on a national rather than sectoral level. They also all focus on ranking policies rather than estimating the welfare gain from switching policies as we do in Section 4. Quirion (2005) takes this ranking idea as far as possible based on theory. Zhao (2018), Branger and Quirion (2014) and Newell and Pizer (2008) provide welfare expressions but again focus on numerical applications that rank policies, rather than estimating the actual welfare difference.

The welfare expressions in these last three papers comparing a TPS versus a feebate are complicated (Equation (27) in Zhao, Equations (E.3) in Branger and Quirion, and (23) in Newell and Pizer). As we describe below, their cost model is not well-suited to compare TPS and feebate policies, resulting in more complex and less interpretable results. More importantly, the model may be less appropriate for capturing sectoral (versus economywide) cost uncertainty. We turn to these modeling choices in the section that follows as well as how our results compare to all of these more closely related papers.

\section{Welfare analysis of TPS versus Feebate}

In this section we build a model of mitigation costs and benefits to derive the welfare advantage of feebates compared to TPSs. We build this model in unit-cost space where the cost per unit of output depends on the reductions per unit of output. This contrasts with most of the preceding literature (except the Kellogg papers and the early Quirion paper) which focus on total costs and total emissions. This matters when we consider uncertainty about output as well as costs.

We consider the unit-cost, rather than the total-cost, formulation to be a more natural formulation for modeling TPSs and feebates. As we show, this approach leads to a simple adjustment to Weitzman's results. We also believe unit costs and unit-cost shocks may be a more sensible model, which we now discuss.

\subsection{Unit cost function and cost shocks}

We begin with our cost function, given by 


$$
\frac{C(q)}{x}=c(r)=c_{0}+\left(c_{1}+\theta_{c}\right)\left(r-r^{*}\right)+\frac{c_{2}}{2}\left(r-r^{*}\right)^{2} .
$$

where $q$ is emissions, $x$ is output, $r=q / x$ is the emissions rate per unit of output $x$, the parameters $c_{n}$ are a quadratic approximation around an arbitrary emissions rate $r^{*}$, and $\theta_{c}$ introduces uncertainty. We assume convex costs so $c_{2} \geq 0$. $\theta_{c}$ is mean-zero with variance $\sigma_{c}^{2}$. A positive value of $\theta_{c}$ raises the marginal (unit) cost schedule for "producing" $r$. We assume output has mean $\bar{x}$ and variance $\sigma_{x}^{2}$ and, for the moment, ignore possible correlation between $x$ and $\theta_{c}$.

Meanwhile, the Weitzman (1974) cost function is given by

$$
C^{W}(q)=c_{0}^{\mathrm{W}}+\left(\mathrm{c}_{1}^{\mathrm{W}}+\theta_{c}^{W}\right)\left(q-q^{*}\right)+\frac{c_{2}^{W}}{2}\left(q-q^{*}\right)^{2} .
$$

where all variables are as before but the approximation is now around an arbitrary emission level $q^{*}$ and we use superscripts $\mathrm{W}$ to denote the Weitzman formulation.

An important distinction arises when we consider marginal costs and the emissions response functions. In particular, marginal costs under models (2) and (1) are given by

$$
\begin{gathered}
\frac{d C^{W}(q)}{d(-q)}=-\left(c_{1}^{W}+\theta_{c}^{W}\right)-c_{2}^{W}\left(q-q^{*}\right) . \\
\frac{d C(q)}{d(-q)}=-\frac{d c(r)}{d r} \frac{d r}{d q} x=-\frac{d c(r)}{d r}=-\left(c_{1}+\theta_{c}\right)-c_{2}\left(r-r^{*}\right) .
\end{gathered}
$$

Here, we have taken derivatives with respect to reducing emissions, $-q$, to highlight our focus on pollution mitigation. That is, marginal costs rise as we move to increasingly lower levels of pollution. Therefore, when we construct figures, marginal costs will be downward sloping in emissions as $c_{2} \geq 0$. Consider now the emissions response functions, where prices are fixed at $p$ and firms respond by setting marginal cost equal to the price. The respective response functions are given by

$$
\begin{aligned}
& q^{W}=q^{*}-\frac{c_{1}^{W}+\theta_{c}^{W}}{c_{2}^{W}} \\
& q=x\left(r^{*}-\frac{c_{1}+\theta_{c}}{c_{2}}\right)
\end{aligned}
$$

Herein lies an important difference. Using our unit cost function with unit-cost 
shocks, emissions for a given price and value of $\theta_{c}$ will scale with output. Put another way, the emissions rate will remain fixed as $x$ varies. Under a Weitzman-style cost function with total costs shocks, however, the emission level for a given price and value of $\theta_{c}$ remain fixed as output fluctuates - and, in turn, the emissions rate will vary as $x$ varies. Even with correlation between $x$ and $\theta_{c}$ in Equation (5), it is impossible for the emissions rate to remain fixed as $x$ varies because of the fixed $q^{*}$ term.

This finding has implications for the comparative advantage of feebates versus TPS. Using our cost function and absent correlation with $\theta$, variation in $x$ will not affect the emissions rate under either a TPS or a feebate that fixes the price. Intuitively, uncertainty about $\theta_{c}$ will then create the only difference between the feebate and a TPS. Using Weitzman's cost function, even if $\theta_{c}$ is fixed at zero, a TPS and feebate will deliver different outcomes as $x$ varies.

There are a variety of reasons why cost shocks at the unit-cost level may be a more sensible assumption in the real world. In most sectors, mitigation choices depend-at least over the longer-term — on unit technology costs. For motor vehicles, there are choices of adding technology to increase the fuel economy per car. For motor fuels, there are blending and other choices that operate per gallon. For electricity, costs often rise with higher shares of a particular technology (e.g., as an increased renewable share requires more battery storage). In all of these cases, unexpected technological progress (or lack thereof) will take the form of changes in unit mitigation cost. We therefore view shocks in the marginal cost versus emissions-per-unit-output space, at least at the sectoral level, to be equally if not more plausible than shocks in the marginal cost versus emissions space.

\subsection{Unit benefit function and representation in unit-cost space}

We follow Weitzman's benefit function of emissions $q$, which is a local quadratic approximation using parameters $b_{n}$ about an arbitrary quantity $q^{*}$ :

$$
B(q)=b_{0}+b_{1}\left(q-q^{*}\right)-\frac{b_{2}}{2}\left(q-q^{*}\right)^{2} .
$$

We abstract from the notion of benefit shocks because we know, from Weitzman's work, that they do not play a role in the comparative advantage expression. We assume concave benefits such that $b_{2} \geq 0$. This allows us to represent marginal benefits as

$$
\begin{aligned}
\frac{d B(q)}{d(-q)} & =-b_{1}+b_{2}\left(q-q^{*}\right) \\
& =-b_{1}+b_{2} \bar{x}\left(\left(1+\frac{x-\bar{x}}{\bar{x}}\right) r-\frac{q^{*}}{\bar{x}}\right)
\end{aligned}
$$

where we have again taken the derivative with respect to reducing emissions. As a negative externality, mitigation benefits rise at higher $q$ (and $r$ ). Therefore, marginal benefits will be upward sloping in our figures. Also, note that unlike marginal costs in Equation (4), marginal benefits expressed in terms of the emissions rate $r$ depends on output $x$. 
We graph expected marginal costs against expected marginal benefits (based on the expectation of Equation (8)) in Figure 1. Without loss of generality, we have assumed $q^{*}=r^{*} \bar{x}$ and $b_{1}=c_{1}$. Note $b_{1}=c_{1}$ are negative, based on the idea that we are spending resources to reduce emissions, and emission reductions are what create benefits. This serves to identify the intersection of the expected schedules given by Equations (4) and (8) as $\left[r^{*},-b_{1}\right]$, but as we shall see, the only parameters that matter for the comparative advantage are $b_{2}, c_{2}, \sigma_{c}^{2}, \bar{x}$ and $\sigma_{x}$.

We note that graphing prices versus emissions rate (the "unit cost space") is useful for representing policies. A TPS fixes the emissions rate and emissions rate is represented by a vertical line, while a feebate fixes marginal cost and is represented by a horizontal line. As the marginal cost schedule (4) is realized based on values of $\theta_{c}$, the outcomes can be read off the actual (versus expected) marginal cost schedule in the figure.

We also note that equating these expected marginal costs and benefits does not define the optimal TPS. That is because the vertical axis is the expected derivative of costs and benefits with respect to emissions, plotted against the emissions rate. To determine the optimal TPS, we want to consider the expected derivative of both costs and benefits with respect to the emissions rate and then identify the emissions rate where those two derivatives are equal, which we now do.

\subsection{Optimal TPS Rate}

We now find the social optimal TPS rate $r_{T}$ by matching the marginal benefit of decreasing $r$ with the marginal cost. That is, we equate

$$
E\left[\frac{d B}{d(-r)}\right]=E\left[\frac{d C}{d(-r)}\right]
$$

The expectation of the cost derivative is easily computed (recalling our assumption that $x$ and $\theta_{c}$ are uncorrelated),

$$
\begin{aligned}
E\left[\frac{d C}{d(-r)}\right]=E & {\left[\frac{d}{d r}\left[-x\left(c_{0}+\left(c_{1}+\theta_{c}\right)\left(r-r^{*}\right)+\frac{c_{2}}{2}\left(r-r^{*}\right)^{2}\right)\right]\right] } \\
& =E\left[-x\left(\left(c_{1}+\theta_{c}\right)+c_{2}\left(r-r^{*}\right)\right)\right] \\
& =\bar{x}\left(-c_{1}-c_{2}\left(r-r^{*}\right)\right)
\end{aligned}
$$

The expectation of the benefit derivative is more complex,

$$
\begin{aligned}
E\left[\frac{d B}{d(-r)}\right] & =E\left[\frac{d B}{d q} \frac{d q}{d(-r)}\right] \\
& =E\left[-\left(b_{1}-b_{2}\left(r x-r^{*} \bar{x}\right)\right) x\right] \\
& =\bar{x}\left(-b_{1}+b_{2} \bar{x}\left(r\left(1+v_{x}^{2}\right)-r^{*}\right)\right) .
\end{aligned}
$$

where $v_{x}^{2}=\sigma_{x}^{2} / \bar{x}^{2}$. We can divide both expressions by $\bar{x}$ and view them in Figure 1 . 
In particular, the marginal cost schedule is the same, but the marginal benefit schedule appropriate for determining the optimal TPS has a steep slope. Uncertainty about $x$ translates into variation in emissions uncertainty under a rate control that makes the relevant marginal benefit schedule steeper. When $r=0$, this effect vanishes; thus, the vertical intercept of the two schedules is the same. Otherwise, expected marginal benefits are higher at every level of mitigation, because raising $r$ raises this variation.

Equating Equations (9) and (10) and recalling $b_{1}=c_{1}$, we can solve for the optimal TPS rate:

$$
r_{T}=\frac{\left(b_{2} \bar{x}+c_{2}\right)}{b_{2} \bar{x}\left(v_{x}^{2}+1\right)+c_{2}} r^{*}
$$

Note that $r_{T}<r^{*}$ so long as $x$ is uncertain.

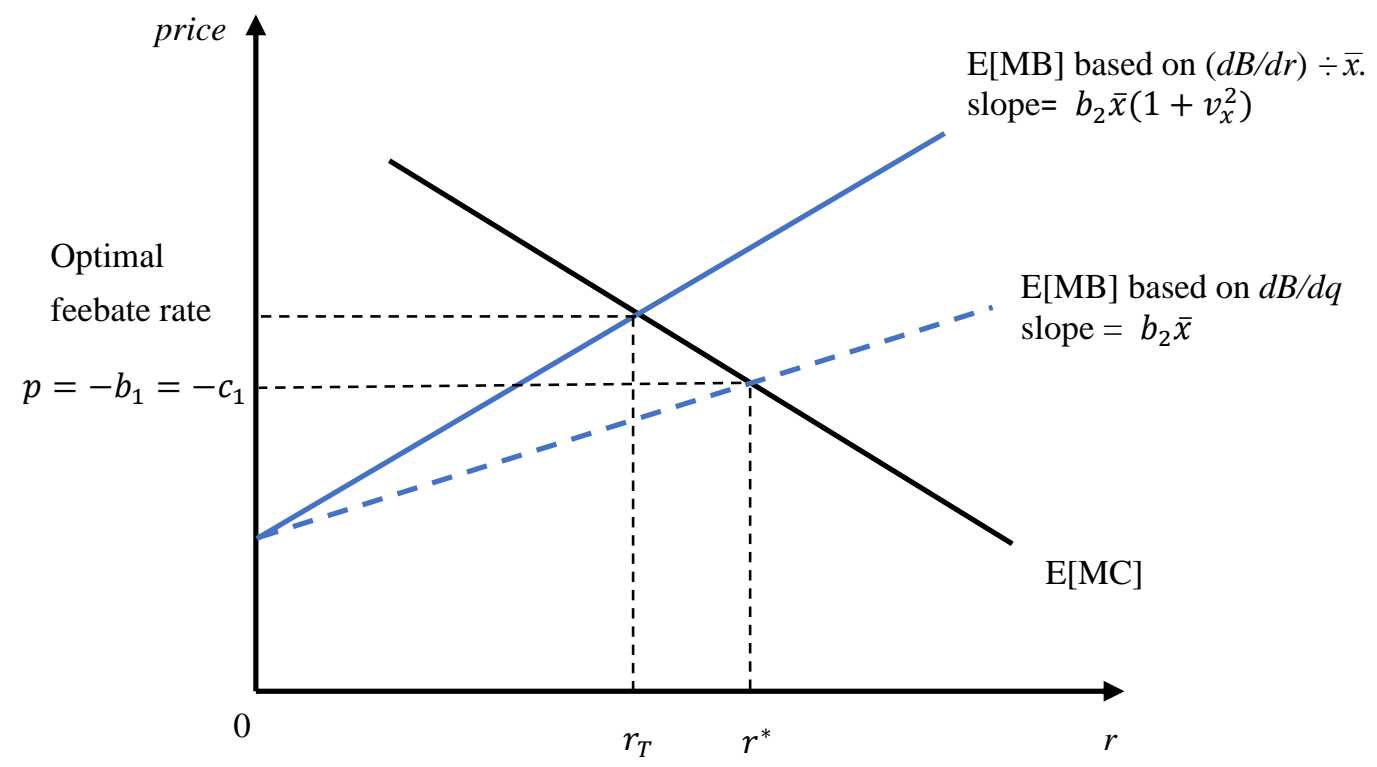

Figure 1. Optimal Rate for Tradable Performance Standard

\subsection{Feebates versus TPS}

We now consider the response function for a feebate, in order to first understand the optimum feebate and then to derive the comparative advantage relative to a TPS. A feebate is based on a fee or rebate levied on emissions above or below a "pivot" point. Letting $r_{f}$ be the pivot point and $P$ be the emission fee, the feebate equals $p\left(r-r_{f}\right) x$. We assume an aggregate firm facing this feebate alongside the unit cost function Equation (1). 
Minimizing costs, the firm will choose $r$ to minimize $p\left(r-r_{f}\right) x+c(r) x$, choosing

$$
r=r^{*}-\left(p+c_{1}+\theta_{c}\right) / c_{2} \text {. }
$$

To find the optimal feebate, we need to take the expectation of the derivative of net benefits with respect to $p$ and solve for that expected derivative being equal to zero. From the intermediate steps in Equations (9) and (10), we know that

$$
\begin{aligned}
& \frac{d N B}{d r}=\left(b_{1}-b_{2}\left(r x-r^{*} \bar{x}\right)\right) x-x\left(\left(c_{1}+\theta_{c}\right)+c_{2}\left(r-r^{*}\right)\right) \\
& =-b_{2}\left(r x-r^{*} \bar{x}\right) x-x \theta_{c}-x c_{2}\left(r-r^{*}\right)
\end{aligned}
$$

(using $b_{1}=c_{1}$ ). We can then substitute (12) into this expression for $r$, multiply by $d r / d p$ $=-1 / c_{2}$, and take expectations, yielding

$$
\begin{aligned}
& E\left[\frac{d N B}{d r} \frac{d r}{d p}\right] \\
& =E\left[\frac{-b_{2}\left(\left(r^{*}-\left(p+c_{1}+\theta_{c}\right) / c_{2}\right) x-r^{*} \bar{x}\right) x-x \theta_{c}-x c_{2}\left(-p-c_{1}-\theta_{c}\right) / c_{2}}{-c_{2}}\right] \\
& =\frac{\bar{x}\left[b_{2} \bar{x}\left(\left(r^{*}-\frac{p+c_{1}}{c_{2}}\right)\left(1+v_{x}^{2}\right)-r^{*}\right)-c_{2} \frac{p+c_{1}}{c_{2}}\right]}{c_{2}}
\end{aligned}
$$

Setting this equal to zero solving for $p_{F}$, we have

$$
p_{F}=-c_{1}+c_{2} \times \frac{b_{2} \bar{x} v_{x}^{2} r^{*}}{c_{2}+b_{2} \bar{x}\left(1+v_{x}^{2}\right)}=-c_{1}+c_{2}\left(r^{*}-r_{T}\right)
$$

This shows that the optimal feebate is simply the price that corresponds to $r_{T}$ along the marginal cost schedule in Figure 1.

At this point, it should become more apparent that our model mimics Weitzman's model but in unit cost space, with a marginal cost slope $c_{2}$ and marginal benefit slope given by

$$
b_{2} \bar{x}\left(1+v_{x}^{2}\right)
$$

With that in mind, we posit our final result, that the comparative advantage (expected welfare difference) between feebates and TPS is given by

$$
\Delta_{F-T}=\frac{\sigma_{c}^{2} \bar{x}\left[c_{2}-b_{2} \bar{x}\left(v_{x}^{2}+1\right)\right]}{2 c_{2}^{2}} .
$$

This mimics Weitzman's results with (a) our modified benefit slope, where more output variations favors TPS, and (b) multiplying Weitzman's expression by $\bar{x}$ to obtain the total 
welfare difference (rather than the per-unit welfare difference). A detailed derivation is given in Appendix B.

Our results in the rate-based context are straightforward and can be viewed as analogous to Weitzman's finding: if the marginal costs curve is steeper than the expected marginal benefit curve, then feebates outperform TPS, and vice versa (Figure 2).

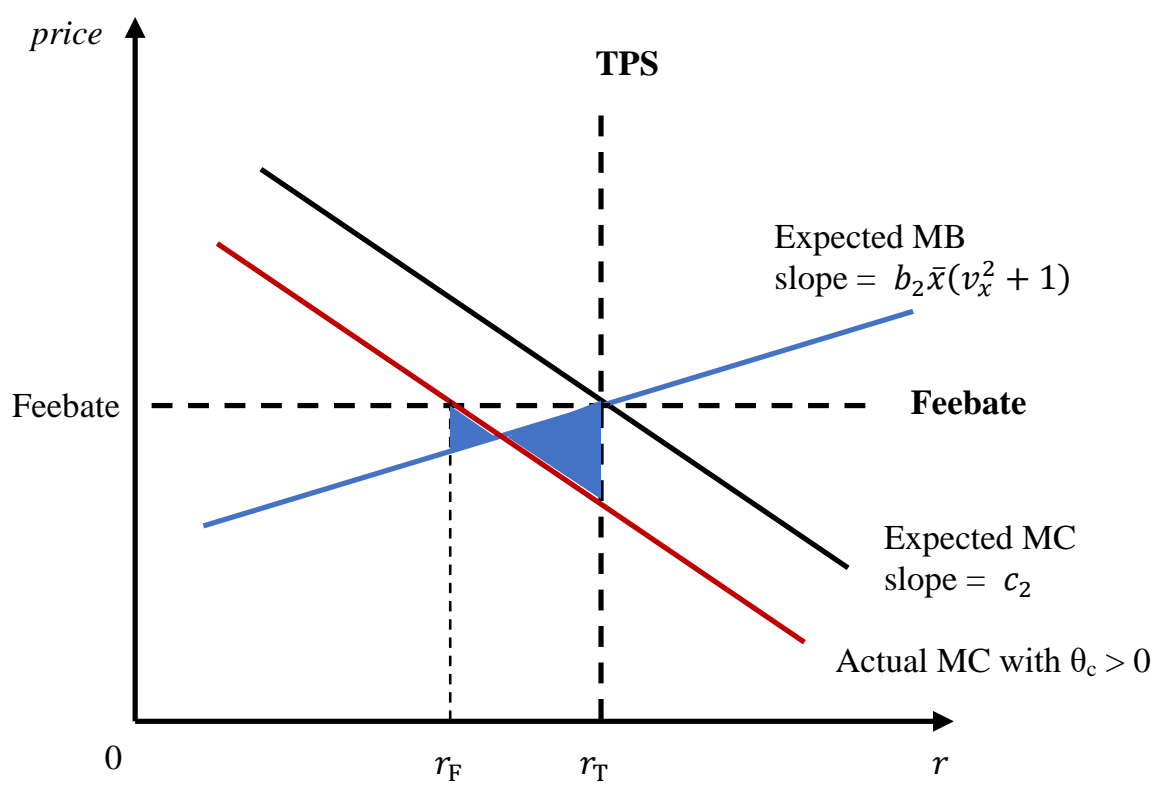

Figure 2. Feebates versus TPS

Our results appear most similar to Quirion's (2005) Equation (14). ${ }^{2}$ That equation suggests TPS ("relative cap" in his terminology) is preferred to a price policy when marginal benefits are steeper than marginal costs, multiplied by an adjustment related to output variation ("baseline emissions" in his formulation). In turn, we both find that increased output variation tilts the expression towards TPS so long as $b_{2}>0$. However, he does not provide expressions for the actual comparative advantage, like our Equation (14), making it more difficult to compute dollar gains for different applications as we do in Section 4. We are also interested in how the results change when cost and output shocks are correlated, which we now discuss.

As hinted earlier, if we allow for correlation between $\theta_{c}$ and $x, \sigma_{c x}$, positive correlation will always tilt the expression (14) towards a TPS and negative correlation will generally tilt it towards a feebate. In particular, we derive the following expanded result in Appendix B

\footnotetext{
${ }^{2}$ When $b_{2}=0$, focusing on the unit case $(\bar{x}=1)$, our Equation (14) also matches Kellogg's (2018) Equation (35). His $B_{e e}$ equals our $c_{2}$ and his $B_{e G} \sigma_{c}$ equals our $\sigma_{c}$.
} 


$$
\Delta_{F-T}=\frac{\sigma_{c}^{2} \bar{x}\left[c_{2}-b_{2} \bar{x}\left(v_{x}^{2}+1\right)\right]}{2 c_{2}^{2}}-\frac{b_{2} \bar{x}\left(1+v_{x}^{2}\right)}{c_{2}} r_{T} \sigma_{c x}-\frac{b_{2}}{2} \frac{\sigma_{c x}^{2}}{c_{2}^{2}}
$$

To understand this result, consider that a feebate introduces variance in the emissions rate based on Equation (6), versus a TPS that fixes the rate. Based on the convexity of costs and concavity of benefits, the direct effect is to raise costs and lower benefits. Positive correlation between $x$ and $\theta_{c}$ exacerbates this effect, worsening expected welfare under the feebate. Meanwhile, negative correlation ameliorates the effect raising expected welfare under a feebate. When cost variation is large enough, particularly when the standard deviation of shocks in rate space $\left(\sigma_{\mathrm{c}} / c_{2}\right)$ is larger than twice the TPS rate $r_{T}$, even negative correlation can eventually hurt feebates relative to TPS (a condition discussed in more detail in the appendix).

Finally, we note that expression (14) and (15) appear quite different compared to Zhao's Equation (27), Newell and Pizer's Equation (23) and Branger and Quirion's Equation (E.3). All three are more complicated expression for the comparative advantage of prices versus indexed, intensity, or relative quantities (their equivalent of feebate versus TPS). ${ }^{3}$ The main reason is the difference in the response function under price policies, noted above. Our expression for emissions under a given price is given by Equation (6) and theirs by Equation (5) (or a close variation). In particular, our cost model and response function implies behavior under a price policy that is much closer to a TPS. The only difference between TPS and feebate policy outcomes in our model is the cost shock $\theta_{c}$ shifting either the emissions rate or the price holding the other constant. Meanwhile, under the other three cost models and response functions, TPS and price policy outcomes differ based on both cost shocks $\theta_{c}$ and $x$ variation. For this reason, our comparative advantage simplifies and theirs does not. ${ }^{4}$ As we argue in Section 3.1, not only does our approach make the algebra simpler, it also corresponds to a natural way to think about technology uncertainty in a sectoral context.

\section{Applying the model: the case of ETS of China's Power Sector and}

\section{California LCFS}

We now apply our analytical model to calculate the welfare advantage of a feebate over a TPS in two cases: China's national carbon market and California's low carbon fuel standard.

\footnotetext{
3 Zhao (2018) does not present a comparative advantage expression

${ }^{4}$ Indeed, the papers draw different conclusions regarding the effect of higher output variability. For example, $\mathrm{n}$ Newell and Pizer, such variability is ultimately bad for a TPS because it introduces variability in emissions, lowering welfare; there is no comparable effect for a price policy. In our expression (14), this unambiguously will favor a TPS. The adverse effect in Newell and Pizer similarly affects both a TPS and the price policy.
} 


\subsection{China's national carbon market}

China announced its launch of a national carbon market on December 19, 2017. The market will start with the power sector. Generators whose annual emissions are greater than 26 thousand tons of $\mathrm{CO}_{2} \mathrm{e}$ (or whose annual energy consumption is greater than 10 thousand tce) are required to comply with the regulation. Over 2000 coal-fired generators, which collectively emit about one-third of the country's $\mathrm{CO}_{2}$ emissions, will be regulated.

The new carbon market in China is a tradable performance standard (Goulder et al. 2017; Pizer and Zhang 2018; Goulder and Morgenstern 2018; Goulder et al. 2019). It allocates allowances according to a rate (benchmark) and the actual output (power generation) in that year (Ministry of Ecology and Environment, P. R. China 2020). Therefore, the realized emissions vary with the realized output level. While the benchmark standard will be achieved in the aggregate, individual plants and firms may emit above or below the standard. The national market is considering managing allowance prices in the form of a hybrid system.

Here we estimate the welfare gain if China used a feebate rather than a TPS, providing a bounding estimate of the potential gains from limiting allowance price variability. Assuming $b_{2}$ is essentially zero (Newell and Pizer 2003), the parameters needed in Equation (14) are the slope of marginal cost $\left(c_{2}\right)$, the standard error of unit cost shocks $\left(\sigma_{c}\right)$, and the average output $(\bar{x})$.

We use two cost models of China's power sector to calibrate our model: (1) the GCAM model from the Pacific Northwest National Lab's Joint Global Change Research Institute (Yu et al. 2019), and (2) the Earth DNE-21+ model from the Research Institute of Innovative Technologies. We use two scenarios for each model giving emissions, electricity output and the corresponding $\mathrm{CO}_{2}$ price in the year 2030, and compute emissions rate. We do a simple regression of carbon price against emissions rate for the four data points and find $c_{2}=130 \$ \cdot \mathrm{MWh} /$ tons $^{2}$ and $\sigma_{c}=22 \$ /$ ton. Figure 3 plots the marginal cost curves for these two models alongside the fitted line and $+/-$ two standard deviations. Finally, the average output level given by the two models is $\bar{x}=8,282 \mathrm{TWh}$. Therefore, the welfare gain if a feebate were applied instead of a TPS for China's power sector carbon market would be:

$$
\Delta_{F-T}=\frac{\sigma_{c}^{2} \bar{x}}{2 c_{2}}=\frac{22^{2} \cdot 8,282}{2 \cdot 130}=\$ 15 \text { billion }
$$




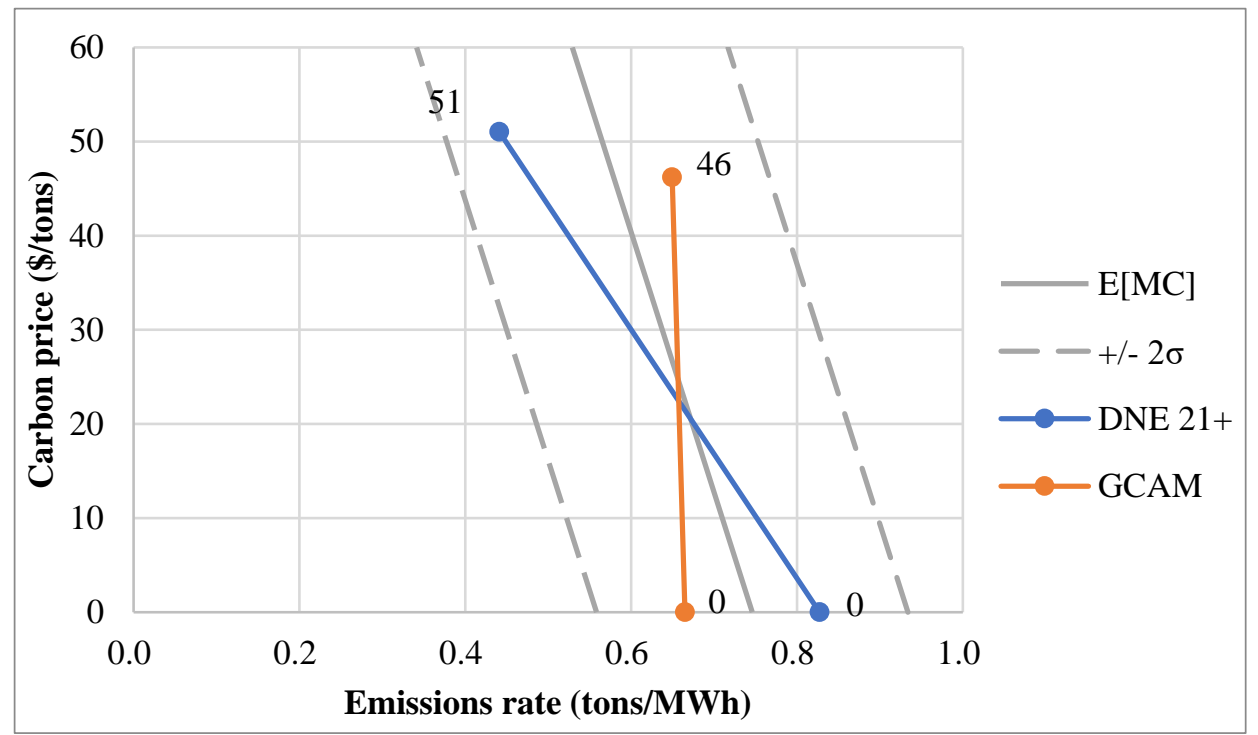

Figure 3. Marginal Cost Curves of China's Power Sector

This is the annual dollar gain for any feebate and TPS designed to achieve the same target on average in the Chinese power market. To put this into context, we compare this dollar value to estimates of the baseline, expected total abatement cost under different TPS scenarios. Note that there is no change in benefits moving from a TPS to feebate, given our assumption that $b_{2}=0$. Both have the same expected emissions and expected benefits depend only on expected emissions, not variation in emissions, when $b_{2}=0$. Thus, expected TPS costs are a reasonable way to normalize the feebate savings.

The total abatement cost for a TPS in a linear marginal cost model is given by

$$
E\left[\frac{1}{2} \Delta q p\right]=\mathrm{E}\left[\frac{1}{2 \mathrm{c}_{2}} x p^{2}\right]=\frac{1}{2 \mathrm{c}_{2}} \bar{x} E\left[p^{2}\right]=\frac{1}{2 \mathrm{c}_{2}} \bar{x}\left(E[p]^{2}+\sigma_{c}^{2}\right)
$$

where $\frac{p}{c_{2}}=\Delta r x=\Delta q$ is the amount of reduction in emissions as we move from a (unregulated) price of zero to a TPS price $p$ in order to achieve $r=r_{T}$. The cost function variance $\sigma_{c}^{2}$ equals the difference $E\left[p^{2}\right]-E[p]^{2}$. We show this in more detail in Appendix C.1.

To obtain price estimates, we turn to both China's pilot carbon trading experiences in the past few years as well as recent studies of price expectations for the future national market. China has operated seven regional trading experiments in five cities (Beijing, Shanghai, Shenzhen, Tianjin, Chongqing) and two provinces (Guangdong, Hubei) since 2013. The average price of these pilots is about $5 \$ /$ ton $(35 \mathrm{CNY} /$ ton, assuming 1 $\mathrm{CNY}=0.15$ USD). According to one recent study, ${ }^{5,6}$, the average expectation of China's

5 http://www.chinacarbon.info.

6 The respondents of the survey include professionals from industry, consultancies, academia, carbon finance, NGO, carbon exchanges and industry associations. 
Table 1 Percentage Welfare Gains of Feebate of China's National Carbon Market

\begin{tabular}{|c|c|c|c|c|}
\hline & Expected price under TPS $E[p]$ (\$/ton) & 5 & 14 & 25 \\
\hline (1) & Total cost $(E[p])^{2} \bar{x} / 2 c_{2}$ (billion $\left.\$\right)$ & 0.8 & 6.2 & 20 \\
\hline (2) & Maximum positive shock, $\theta_{\max }$ & $0.227 \sigma_{c}$ & $0.636 \sigma_{c}$ & $1.14 \sigma_{c}$ \\
\hline (3) & $E\left[\left(\theta_{c}^{\prime}\right)^{2}\right]$ with truncated normal $(\$ / \text { ton })^{2}$ & 124 & 286 & 400 \\
\hline (4) & Total expected cost $E\left[p^{2}\right] \bar{x} / 2 c_{2} \quad$ (billion $\$$ ) & 4.8 & 15.3 & 32.6 \\
\hline (5) & $\Delta_{F-T}$ (billion $\left.\$\right)$ (no truncation) & 15 & 15 & 15 \\
\hline (6) & $\Delta_{F-T}($ billion $\$)($ truncated $)$ & 4.0 & 9.1 & 13 \\
\hline (7) & Savings & $83 \%$ & $59 \%$ & $39 \%$ \\
\hline
\end{tabular}

carbon price in 2025, 2030 and 2050 are 11, 14 and $25 \$$ ton respectively (71, 93 and 167 $\mathrm{CNY} /$ ton) (Slater et al. 2020). Therefore, we calculate the percentage saving from switching to a feebate under three price scenarios: $5 \$$ ton (current average price in pilots), $14 \$$ ton (2030 expected price), and $25 \$ /$ ton (2050 expected price) (Table 1$)$.

An immediate complication arises as we think about price variation under a TPS in this example. Namely, the indicated variation coupled with the expected price level would suggest negative prices. That is, with expected prices of 5, 14, and $25 \$$ ton under a TPS and cost shocks whose standard deviation is $22 \$$ ton, a shock that lowers costs by one standard deviation would drive prices below zero in two of the three scenarios unless we impose a non-negativity constraint in the model.

In order to work around this, we replace the error, $\theta_{c} \sim N\left(0, \sigma_{c}\right)$, with an alternative error $\theta_{c}^{\prime}$. In particular, we assume $\theta_{c}^{\prime}=-c_{1}-c_{2} r_{T}=\theta_{\max }$ (where $p=0$ based on (4)) with probability $\pi$ and, with probability $(1-\pi), \theta_{c}^{\prime}$ is distributed as a $N\left(0, \sigma_{c}\right)$ uppertail-truncated at $\theta_{c}^{\prime} \leq \theta_{\max }$. We choose $\pi$ such that $E\left[\theta_{c}^{\prime}\right]=0$. This allows us to continue to use all of our earlier results, which assume $E\left[\theta_{c}\right]=0$ but otherwise did not require distributional assumptions. However, this switch to $\theta_{c}^{\prime}$ changes the variance $\sigma_{c}^{2}$ in Equation (14) to $E\left[\left(\theta_{c}^{\prime}\right)^{2}\right]$. Meanwhile, $E\left[p^{2}\right]$ in Equation (16) becomes $(E[p])^{2}+$ $E\left[\left(\theta_{c}^{\prime}\right)^{2}\right]$. In Appendix C.2, we derive an expression for $E\left[\left(\theta_{c}^{\prime}\right)^{2}\right]$ in terms of $E[p] / \sigma_{c}=\theta_{\max } / \sigma_{c}$, the maximum error (before prices are negative under the TPS) expressed as a multiple of $\sigma_{c}$.

Turning to the results in Table 1, row (1) uses the simpler, $\frac{1}{2 \mathrm{c}_{2}} \bar{x}(E[p])^{2}$ formula to compute the cost at the expected price. Row (2) indicates the number of standard deviations where the positive shock is truncated; e.g., $\theta_{\max }=-c_{1}-c_{2} r_{T}$ from above. Row (3) indicates the variance of the new $\theta_{c}^{\prime}$ error. Row (4) then includes this in the expected cost cacluation. Row (6) adjusts the comparative advantage in row (5) based on this new variance. Finaly Row (7) shows the savings from using feebates over TPS (line 6) as percentage of expected TPS costs (row (6) $\div$ row (4)).

At these low prices, given the considerable uncertainty about costs and TPS price, a price-based approach that targets the same expected emissions rate offers a very 
significant improvement in expeted welfare.

\subsection{California low carbon fuel standard}

California's Low Carbon Fuel Standard (LCFS) is a program that aims to reduce California's greenhouse gas emissions in the transportation sector. The program is implemented under California Assembly Bill AB 32 and is under the administration of California Air Resources Board (CARB). The program started on January 1, 2011. The LCFS sets decreasing standards on fuel suppliers denoted in terms of carbon intensity $\left(\mathrm{gCO}_{2} \mathrm{e} / \mathrm{MJ}\right)$ of transportation fuels. Regulated polluters include oil refineries and fuel distributors that typically incur debits, while alternative fuel suppliers typically create credits. The carbon intensity of all fuels are based on lifecycle analyses of their carbon content. Regulated polluters accumulate LCFS credits if their own intensities are lower than the standards and accumulate deficits otherwise. LCFS credits can be traded or banked, thereby constituting a TPS.

We estimate the potential gain for the LCFS program if feebates were applied instead of a TPS. First, we obtain estimates of marginal cost and the average output from Holland et al. (2015), who estimate the marginal cost of an LCFS for a broad range of targets (Holland et al. 2015). Using that range of estimates we fit a marginal cost schedule in terms of carbon emissions intensity. This yields $c_{2}=238$ ( $\$$. (thousand gallons/ton ${ }^{2}$ ) and $\bar{x}=140$ billion gallons of gasoline equivalent (gge). Next, we calculate the variance of cost shock from the market price of California's LCFS trading market (Figure 4), which gives $\sigma_{c}=33$ (\$/ton). Therefore, for the California LCFS:

$$
\Delta_{F-T}=\frac{\sigma_{c}^{2} \bar{x}}{2 c_{2}}=\frac{33^{2} \cdot 140}{2 \cdot 238}=\$ 320 \text { million }
$$

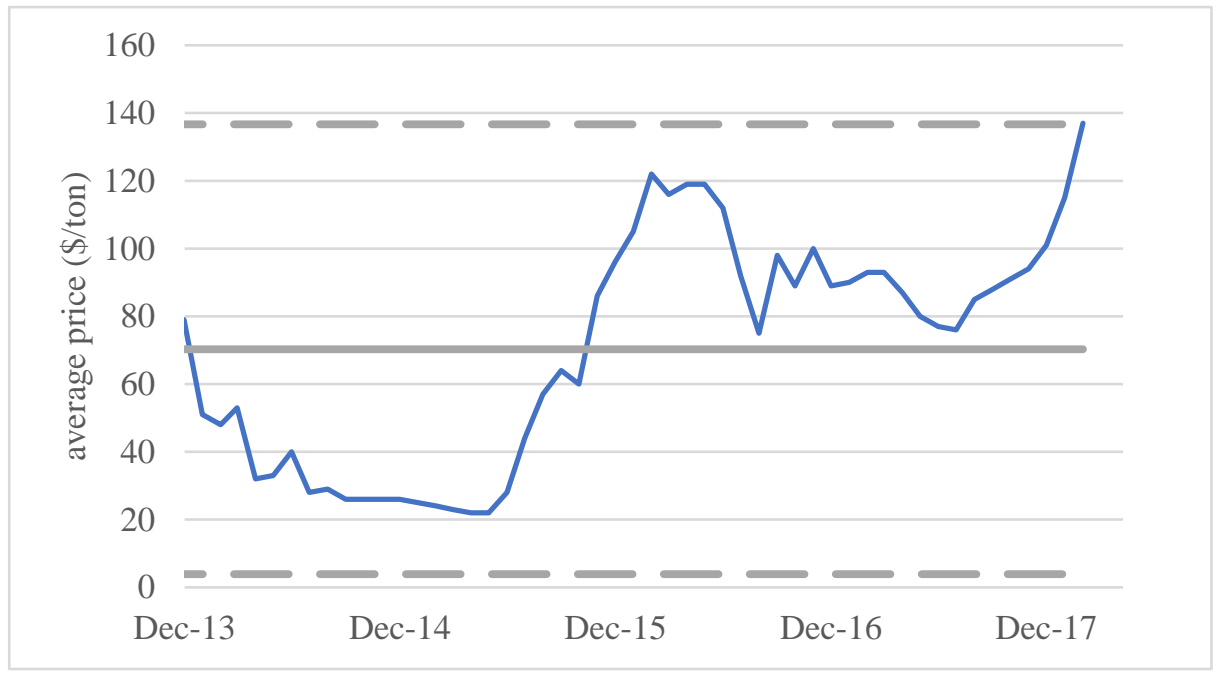

Figure 4. Market Price of California Low Carbon Fuel Standard 
We again compare this welfare gain to the total abatement cost using the above parameters and a number of baseline carbon prices. In particular, we consider 20, 70 and $140 \$$ ton, approximately the lower, average and higher level of the CA LCFS market prices in the above figure. As before, we compute costs under the marginal abatement cost curve as $E\left[\frac{1}{2 c_{2}} \bar{x} p^{2}\right]$, where we also include uncertainty about $p$ in the calculation (and use a truncated normal to deal with the possibility of uncertainty driving the price to zero). Table 2 presents these calculations, analogous to Table 1 . At the central value of $\$ 70 /$ ton, a feebate would offer a nearly $20 \%$ improvement in expected net benefits.

We can look across these two examples, as well as comparing the comparative advantage formula when $b_{2} \approx 0, \frac{1}{2 c_{2}} \bar{x} \sigma_{c}^{2}$, and the total cost formula, $E\left[\frac{1}{2 c_{2}} \bar{x} p^{2}\right]=$ $\frac{1}{2 c_{2}} \bar{x}\left(E[p]^{2}+\sigma_{c}^{2}\right)$, to derive additional intuition. This ratio, row (7) in both tables, is given by

$$
\frac{\Delta_{F-T}}{\mathrm{E}\left[\mathrm{C}_{\mathrm{T}}\right]-\mathrm{E}\left[\mathrm{C}_{\mathrm{p}=0}\right]}=\frac{1}{2 c_{2}} \bar{x} \sigma_{c}^{2} / \frac{1}{2 c_{2}} \bar{x}\left(E[p]^{2}+\sigma_{c}^{2}\right)=\frac{\sigma_{c}^{2}}{E[p]^{2}+\sigma_{c}^{2}}=\frac{v_{p}^{2}}{1+v_{p}^{2}}
$$

When the cost uncertainty, expressed as a coefficient of variation of prices under a TPS, $v_{p}$, is large, the comparative advantage of a feebate ("savings" in the above tables) will be large compared to the expected TPS cost. For example, when $v_{p}=50 \%$ we have $v_{p}^{2}=0.25$ and this savings ratio will be $20 \%$.

\section{Price limits in a tradable performance standard}

In context of climate change, feebates and taxes are preferred over TPSs and ETSs in terms of welfare due to flat marginal benefits. Therefore, adding price elements to an

Table 2 Percentage Welfare Gains of Feebate of CA LCFS

\begin{tabular}{lllll}
\hline \hline & Expected price under TPS $E[p](\$ /$ ton $)$ & 20 & 70 & 140 \\
\hline$(1)$ & Total cost $(E[p])^{2} \bar{x} / 2 c_{2}$ (billion $\left.\$\right)$ & 0.12 & 1.4 & 5.8 \\
$(2)$ & Maximum positive shock, $\theta_{\max }$ & $0.61 \sigma_{c}$ & $2.12 \sigma_{c}$ & $4.24 \sigma_{c}$ \\
$(3)$ & $E\left[\left(\theta_{c}^{\prime}\right)^{2}\right]$ with truncated normal (\$/ton) ${ }^{2}$ & 6219 & 1,067 & 1,08 \\
$(4)$ & Total expected cost $E\left[p^{2}\right] \bar{x} / 2 c_{2} \quad($ billion $\$)$ & 0.26 & 1.8 & 6.1 \\
$(5)$ & $\Delta_{F-T}$ (billion $\left.\$\right)$ (no truncation) & 0.32 & 0.32 & 0.32 \\
$(6)$ & $\Delta_{F-T}$ (billion $\$$ ) (truncated) & 0.18 & 0.31 & 0.32 \\
$(7)$ & Savings & $60 \%$ & $18 \%$ & $5.3 \%$ \\
\hline \hline
\end{tabular}


ETS or TPS will improve welfare. In recent years, price elements have seen increasing importance, particularly in ETSs. In practice, this is implemented through a minimum auction price (to create a price floor) and adding an alternative, fixed \$/ton compliance mechanism (to create a price ceiling). The price ceiling has also seen considerable use in TPSs. However, the mechanical implementation of a price floor within a TPS is not as straightforward. In fact, price floors have not been implemented alongside a TPS to our knowledge. In this section, we discuss the practical issues associated with implementing a price floor in a TPS through with consignment auctions. This hybrid policy mimicks feebates when market prices reach the floor price and therefore offers welfare improvements.

\subsection{Consignment auctions}

Here we discuss one method of implementing a price floor in a TPS: a reserve price implemented via a consignment auction. Other options include government buybacks (which have not been used widely to date) or imposing a regularly updated fee that makes up the difference between a low permit price and the price floor. Such a fee is currently used in the United Kingdom (Aldy 2017). Meanwhile, the consignment approach is used in ETSs in both California's ETS and the Regional Greenhouse Gas Initiative.

Under a consignment mechanism, recipients of allocated permits are required to submit them to an auction and, in turn, receive a share of the auction revenue based on their share of consigned permits. The consignment auction has many advantages compared to alternatives. The approach is revenue neutral, and therefore would not create major financial burdens to governments or firms. The idea of buying back allowances to raise prices requires spending government revenue; the United Kingdom fee approach leads to additional government revenue. The mechanism is automatic as well. Other than holding the prescribed auctions intermittently, no other action is required. Finally, auctions generally have the advantage of ensuring that part or potentially all allowances enter the market, improving transparency, and motivating price discovery compared to a free allocation of allowances (Burtraw and McCormack 2017). However, some authors suggest that this method may not guarantee a clear price signal (Khezr and MacKenzie 2018).

We now turn to some of the implementation choices that arise when using a consignment auction in a TPS rather than an ETS.

\subsection{Implementing the price floor in TPS with full consignment auctions}

To implement the price floor in a TPS with consignment auctions, we require firms to consign their allocated permits to an auction with a price floor. We then distribute the auction revenue based on each firms' share of the total consignment auction.

Formally, we consider a representative firm $i$ in the regulated sector. Firm $i$ will be allocated allowances equal to the product of the performance standard and its output, given 
by $a_{i}=r_{T} x_{i}$. Subscript $i$ now indicates individual firms versus the aggregate. As before, the firm will also accumulate obligations equal to its emissions, which are a product of its own emissions rate and output: $q_{i, s}=r_{i, s} x_{i}$. Here, we add a second subscript $s$, to reflect uncertain states that we will discuss below.

Unlike a typical TPS, however, firms do not receive allocation directly. Instead, the government auctions those allowances on behalf of firms, giving them the auction proceeds. This is referred to as a consignment auction.

We allow a reserve price, $p_{\min }$, in the auction to maintain the floor price. There will be two possible outcomes/states, indicated by $M C_{1}$ and $M C_{2}$ in Figure 5. The first is that the auction is fully covered and clears at $p>p_{\text {min }}$. This is indicated by $M C_{1}$. Firm $i$ receives revenue equaling its allocation times the market price $a_{i} \cdot p$.

We next imagine a function $c_{i, 1}\left(r_{i}\right)$ to be the unit cost function for firm $i$ in case 1 , analogous to Equation (1) but for a single firm and with uncertain outcomes now indexed by a subscript. Recall that we are working to reduce $r$, therefore firms take the cost function derivative with respect to reducing $r$ and set it equal to the market price in order to determine their emissions rate. That is, firms solve $d c_{i, 1}\left(r_{i}\right) / d(-r)=p$ for $r$ to calculate their cost minimizing emissions rate; we label this inverse relation $r_{i, 1}(p)$.

Firms buy permits in the same auction with the clearing price for compliance with expenditure. We can therefore define the firm's gross auction expenditure to be $r_{i, 1}(p) \bar{x}_{i} p$. Recall that consignment auctions are revenue neutral. That is, the total revenue from auction equals the total expenditure of firms that buy allowances in the auction, $\sum a_{i} p=$ $\sum r_{T} x_{i} p=\sum q_{i, s} p=\sum r_{i, 1} x_{i} p$. Therefore, (dividing both sides by $p \sum x_{i}$ ) we have the following result ex post:

$$
\bar{r}_{1}=r_{T}
$$

where $\bar{r}_{1}=\Sigma r_{i, 1} x_{i} / \Sigma x_{i}$, the average emissions rate of regulated polluters in case 1 . The TPS rate $r_{T}$ is exactly maintained when the clearing price is higher than the minimum. Note that each regulated firm's net expenditures are $\left(r_{i, 1}-r_{T}\right) x_{i} p$ and the outcome is the same as a TPS.

The second possibility is that the auction is not fully covered and clears at $p=$ $p_{\text {min }}$, indicated by $M C_{2}$ in Figure 5. In particular, let $r_{i, 2}(p)$ be firm $i$ 's response function in case 2. Moreover, let $\bar{r}_{2}(p)=\sum_{i} r_{i, 2}(p) x_{i} / \sum_{i} x_{i}$, the aggregate emissions rate at price $p$ averaged across all firms in case 2. From the figure, we know that a $p$ such that $\bar{r}_{2}(p)=$ $r_{T} \quad$ would require $p<p_{\min }$ (where the red schedule intersects the vertical line of the supply schedule). Instead, we have $p=p_{\min }$ and $\bar{r}_{2}\left(p_{\min }\right)=\bar{r}_{2}<r_{T}$. Supply is reduced until the aggregate demand supports the minimum price. In this case, firm $i$ 's gross expenditures will be $r_{i, 2} x_{i} p_{\text {min }}$ and its gross revenue $\alpha_{f u l l} a_{i} p_{\text {min }}$, where $\alpha_{f u l l}$ is the reduction in the auction volume for full consignment (here, $\alpha_{f u l l}=\bar{r}_{2} / r_{T}$ ). Each regulated firm's net expenditures at the minimum price is $\left(r_{i}-\bar{r}_{2}\right) x_{i} p_{\min }$. 


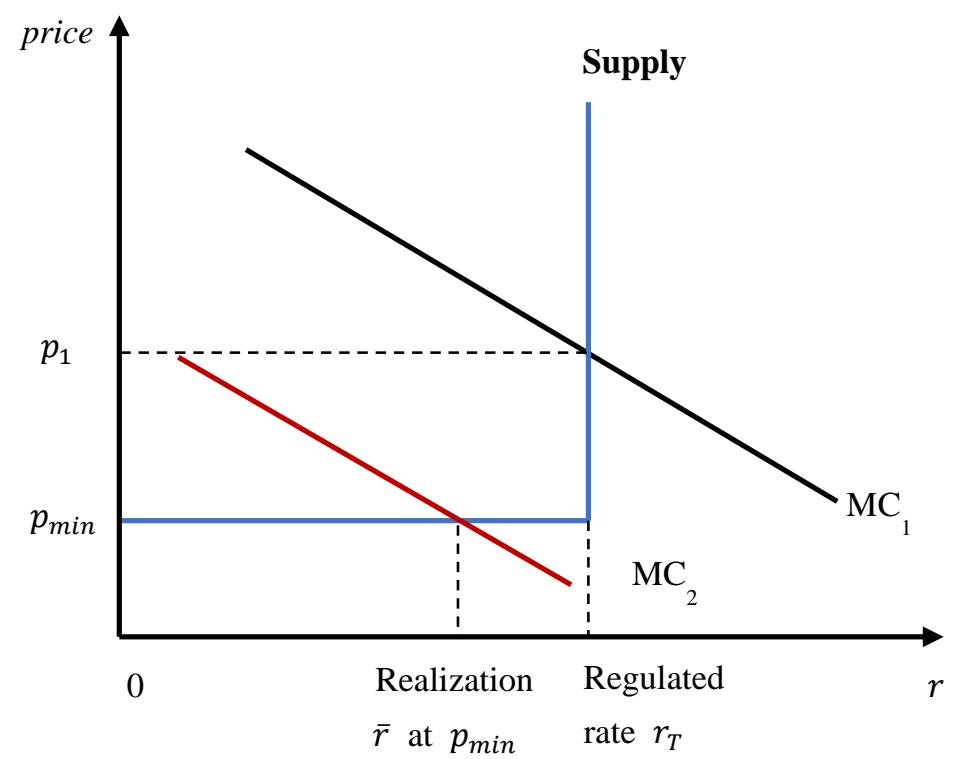

Figure 5. Floor price in a TPS with full consignment

\subsection{Implementing price floor with partial consignment auction}

Policy makers can instead conduct partial consignment auctions to reduce the capital burden on regulated polluters (e.g., that they must first buy allowances in the auction before receiving their auction revenue). The downside is that whatever allocation is not consigned sacrifices some of the policymakers' ability to maintain the floor price.

In this case, a firm will be allocated some allowances directly according to its output and a standard $r_{T, \min }$ lower than the established performance standard $r T$; e.g., $r_{T, \min }<$ $r_{T}$. The firm is not required to consign these allowances. The remainder of the allocated permits, equal to the difference between the two standards, multiplied by the firms' output, $\left(r_{T}-r_{T, \min }\right) x_{i}$, are then consigned. The rest is almost as before-except there is a third case as shown in Figure 6 and gross expenditures are smaller in all cases.

In the first case, as before, the clearing price is higher than the floor. We can show the firm has the same net permit expenditure $\left(r_{i}-r_{T}\right) x_{i} p$ and again $\bar{r}=r_{T}$, so the regulated rate is maintained. However, firm $i$ 's gross expenditure in the auction has declined from $r_{i} x_{i} p$ to $\left(r_{i}-r_{T, \min }\right) x_{i} p$ thanks to a portion of allowances being allocated directly.

In the second case when the market hits the floor price, we again have net expenditures $\left(r_{i, 2}-\bar{r}_{2}\right) x_{i} p_{\min }$ and again $\bar{r}_{2}=\bar{r}\left(P_{\min }\right)$. But like the first case, the auction itself is smaller and gross expenditures in (and revenues from) the auction are reduced. Gross expenditures are reduced, from $r_{i, 2} x_{i} p_{\min }$ to $\left(r_{i, 2}-r_{T, \min }\right) x_{i} p_{\min }$. Meanwhile, gross revenue declines from $\alpha_{f u l l} r_{T} x_{i} p_{\min }$ to $\alpha_{\text {part }}\left(r_{T}-r_{T, \min }\right) x_{i} p_{\min }$. Here, $\alpha_{\text {part }}=\left(\bar{r}_{2}-r_{T, \min }\right) /\left(r_{T}-r_{T, \min }\right)$ is the coverage rate in the partial consignment 
auction in case 2 . It is straightforward to see that $\alpha_{\text {part }}<\alpha_{\text {full }}$.

The advantage of the partial consignment auction comes from the $r_{T, \min } x_{i} p$ reduction in gross expenditures. The disadvantage arises when $\bar{r}\left(p_{\min }\right)<r_{T, \min }$. Even without selling any permits in the consignment auction, the price cannot be maintained at $p_{\text {min. }}$. This gives rise to case 3 , where $\bar{r}_{3}=r_{T, \min }$ and $p<p_{\min }$. This is illustrated by the intersection of $M C_{3}$ and the vertical line at $r_{T, \min }$ in Figure 6. This finding is essentially the rate-based variant of the permit reserve and price ceiling approach proposed by Murray et al. (2009) for ETSs.

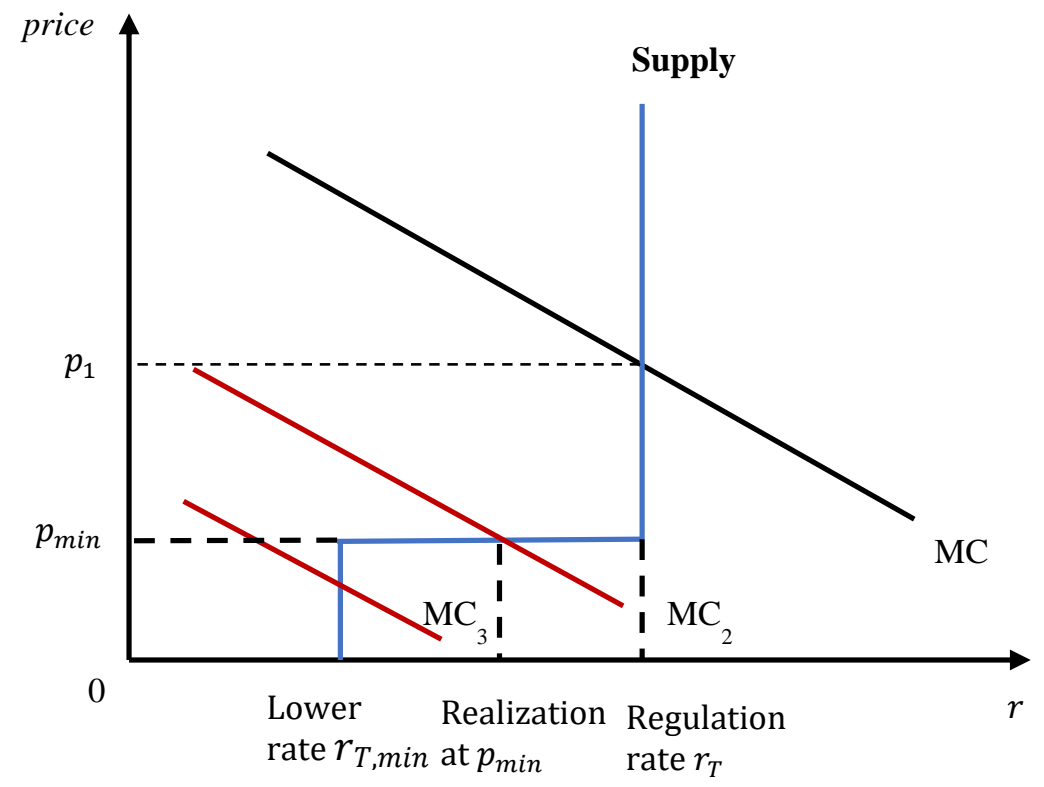

Figure 6. Floor price in a TPS with partial consignment

It is worth noting that the problem with the partial consignment auction arises when there is a reasonable likelihood that $\bar{r}_{S}\left(p_{\min }\right)<r_{T, \min }$ for some uncertain state $s$. By setting $r_{T, \text { min }}<E\left[\bar{r}\left(p_{\text {min }}\right)\right]-2\left(\sigma_{c} / c_{2}\right)$, for example, one can be assured that the minimum price will be maintained $97.5 \%$ of the time (assuming normally distributed cost shocks).

For example, in the $\$ 70$ LCFS case, if we sought a $\$ 50$ price floor, we would want to set $r_{T, \min }<E[\bar{r}(\$ 70 /$ ton $)]-2\left(33 \$ /\right.$ ton $\div 238\left(\$ \cdot 1000 \mathrm{gge} /\right.$ ton $\left.^{\wedge} 2\right)$. We did not provide this information above, but the baseline emissions rate we derive from Holland et al $(2015)$ is 11.16 (tons $/ 1000$ gge). So $\bar{r}(\$ 70 /$ ton $)=11.16$ (tons $/ 1000$ gge $)-\$ 70 /$ ton $\div 238\left(\$ \cdot 1000 \mathrm{gge} /\right.$ ton $\left.^{\wedge} 2\right)$ or 10.87 (tons/1000 gge). Subtracting 2(33\$/ ton $\div 238\left(\$ \cdot 1000 \mathrm{gge} /\right.$ ton $\left.^{\wedge} 2\right)=0.28$, we have $r_{T, \min }<10.59$ (tons $\left./ 1000 \mathrm{gge}\right)$. Thus, the consignment auction would not need to be that large, compared to the volume of direct allocation, in the LCFS case. 


\subsection{Options for unsold permits}

We discuss several options for dealing with unsold permits arising in a consignment auction with a minimum price. We have in mind a multi-period setting where unsold permits might or might not be considered as a part of a cumulative budget or target.

First, unsold permits can simply be confiscated and retired by the government. At the floor price, the market behaves as a price tool and the rate (as well as associated emissions) is adjusted instead. Therefore, retiring the unsold allowances is a direct way to adjust the quantity given a fixed price. However, this approach may be unappealing to participating firms, who view the consigned allowances as their property based on the allowed emissions rate and their indicated production level.

Second, unsold permits could be carried over and added to the consignment auction in the next period. If permit demand in the second period is high enough, all the consigned allowances (including the unsold permits from period one) are auctioned. Firms with unsold consigned allowances from the first period now receive additional revenue. If the demand is not sufficiently high to exceed the minimum price in the second period, the system still maintains the second period minimum price and now generates new unsold permits in period two. Figure 7 shows this possibility of additional unsold allowances in period two (parenthetical superscripts indicate time period).
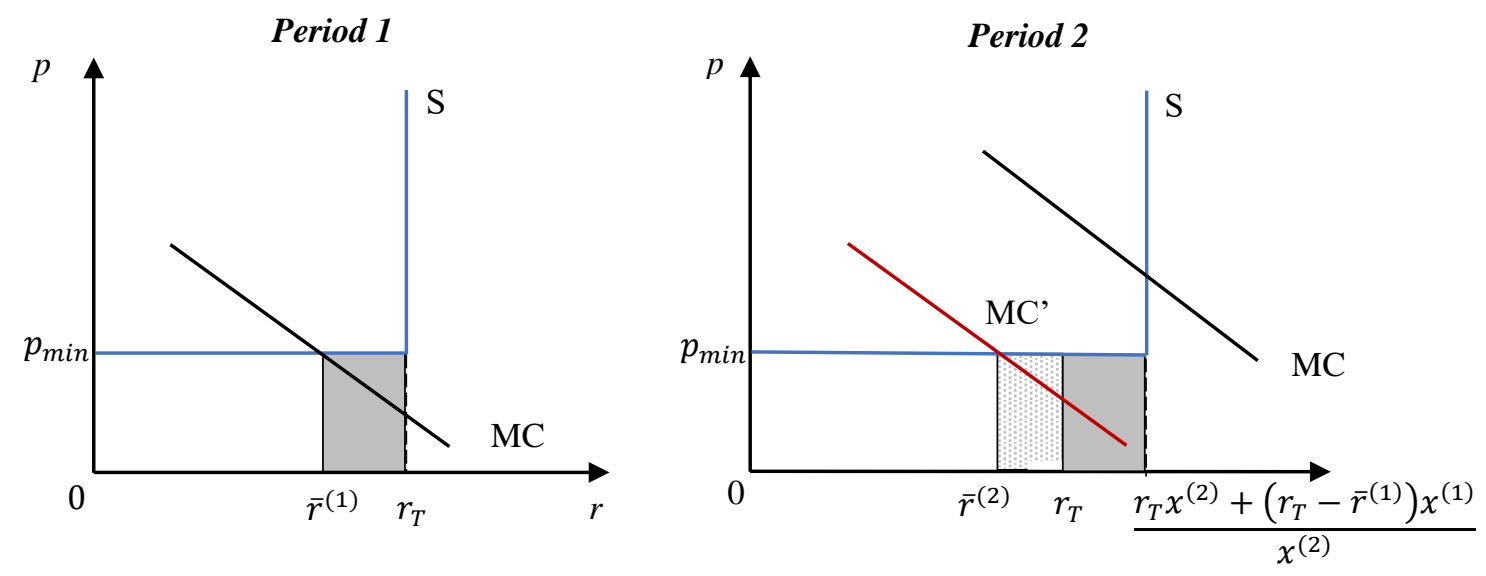

Figure 7. Unsold permits auctioned at minimum price

There are two further options in the next-period-auction: the unsold permits from period one can be prioritized for sale over the newer consigned allowances or vice-versa. If newer consigned allowances are prioritized, the consigners in the second period will get the auction revenue first, and then those in the first period. However, if the unsold permits from period one are prioritized, the consigners from the first period acquire the revenue first (and paid by those in the second period). One downside to this approach is that 
participants in the current period are not paying for their own consigned permits. Instead, they are always paying consigners from previous periods.

A third option is to put unsold permits into a pool for sale at a maximum price, if there is a symmetric, maximum price or high-price permit reserve. In the case of a reserve, this approach could expand the reserve and increase the ability to maintain the price ceiling. If a price ceiling binds, then this approach would redirect what otherwise would be government revenue to the consigners of unsold permits. Figure 8 shows the former example, of an enlarged high-price reserve.
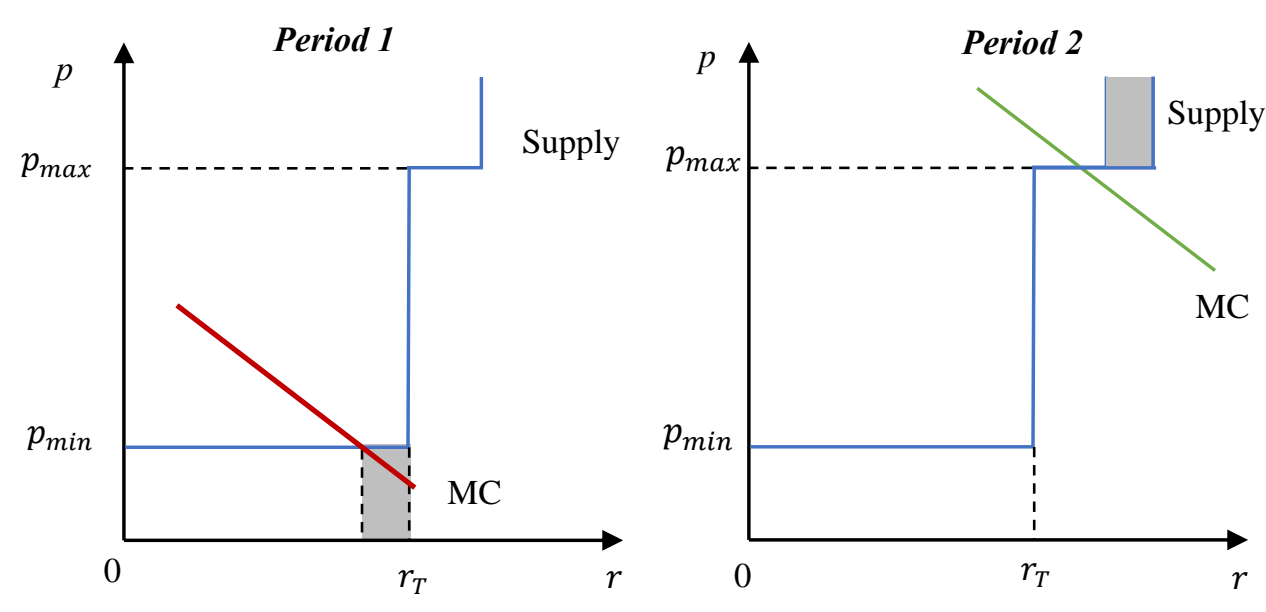

Figure 8. Unsold permits auctioned as part of a high-price reserve

\subsection{Timing issues}

Generally, the allowances need to be auctioned after emissions occur, and more particularly after output is measured, in order to precisely determine the volume of permits to auction based on the established emissions rate. However, most ETS programs issue or auction allowances before or during the period when obligations are entered. For example, in 2020 RGGI held quarterly auctions for its 2020 allowances in March, June, September, and December. In 2020 California held quarterly for both 2020 and a portion of 2023 allowances in February, May, August, and November. If ex-ante allocation is desirable, then one could instead issue or auction allowances based on expected output.

If periodic auctions are allowed during compliance periods, the allocation of auction revenue needs adjustment as the government only knows the exact allocation once the period ends. For example, imagine the above 2020 RGGI auctions where the government only knows output levels for the first quarter in April, the second quarter in July, etc. For the March auction, the government sell $r_{T} \bar{x}_{E}^{(1)}$, where $\bar{x}_{E}^{(1)}$ is the expected first quarter output level. For the June auction, the government then auctions based on 
expected second quarter output and an adjustment for the first quarter, $r_{T}\left(\bar{x}_{E}^{(2)}+\right.$ $\left.\bar{x}^{(1)}-\bar{x}_{E}^{(1)}\right)$. The same process then repeats.

It is worth noting that this same issue arises even without auctions. The government may want to provide permits under a TPS before output is exactly known. Indeed, the Chinese government has taken exactly this approach. They make an initial distribution of allowances based on expected production and then make adjustments in the next period (Munnings et al. 2016).

With consignment auctions, the government has the additional burden of managing not just the volume of allowances but also the return of the allowance proceeds to firms. This might be accomplished by waiting until the second quarter to return proceeds from first quarter allowances. At that point, the actual average price received $\left(p^{(1)} \bar{x}_{E}^{(1)}+\right.$ $\left.p^{(2)}\left(\bar{x}^{(1)}-\bar{x}_{E}^{(1)}\right)\right) / \bar{x}^{(1)}$ is known and can be paid out to each firm based on $x_{i}^{(1)}$.

\section{Conclusion}

Tradable performance standards have earned increasing popularity as a regulatory tool, especially at the sectoral level. However, the use of a price-based alternative (the feebate), the introduction of price controls to a TPS, and features of the TPS policy itself have been less frequently studied compared to their ETS counterparts. Moreover, the idea of a price floor to establish a lower bound on prices has yet to be introduced in a real-world TPS. This is true despite the recent trend of introducing minimum prices in carbon dioxide ETSs. Here, theory suggests expected welfare improvements based on the relatively constant marginal benefits associated with greenhouse gas pollution.

In this paper, we develop a simple analytic model to compare the expected welfare of a TPS and a feebate under cost uncertainty. We employ a unit cost function where the schedule of marginal abatement cost is linear in the emissions rate (emissions per unit output) with additive uncertain shocks. With this formulation, the Weitzman comparative advantage expression continues to hold with a simple adjustment to the marginal benefit slope based on output variation. Moreover, we show that the comparative advantage expression varies almost monotonically with any correlation between output and the cost shock (the exception occurring with negative correlation when the uncertainty in emission rates under a feebate is large compared to the expected emission rate).

We apply the model to two cases: the Chinese national carbon market and the California Low Carbon Fuel Standard. In both cases we find relatively large gains associated with switching from a TPS to a feebate, a savings of roughly 60 and 20 percent, respectively, expressed as a share of total expected costs under the TPS. We argue this is a general result when the coefficient of variation in emission price under at TPS is larger than 
roughly one-half.

We also discuss implementation choices related to establishing a price floor for a TPS. Price floors are typically implemented in emission trading programs through establishing a reserve price in a permit auction. Because of the direct allocation of permits under a TPS based on output, such an approach is not immediately available. We therefore discuss the possibility of full or partial consignment auctions as well as advance auctions based on expected output, which serve as a practical path forward for incorporating price floors into TPSs.

\section{References}

Adamou, Adamos, Sofronis Clerides, and Theodoros Zachariadis. 2014. "Welfare Implications of Car Feebates: A Simulation Analysis." The Economic Journal 124 (578): F420-43. https://doi.org/10.1111/ecoj.12094.

Aldy, Joseph E. 2017. "The Political Economy of Carbon Pricing Policy Design." Discussion Paper ES 17-7. Harvard Project on Climate Agreements. https://www.belfercenter.org/sites/default/files/files/publication/aldy-ets-taxfinal.pdf.

Barbose, Galen. 2019. "U.S. Renewables Portfolio Standards: 2019 Annual Status Update." Lawrence Berkeley National Laboratory. https:/emp.lbl.gov/publications/usrenewables-portfolio-standards- 2 .

Becker, Jonathon M. 2020. "Tradable Performance Standards in a Dynamic Context." 2020-03. Working Papers. Working Papers. Colorado School of Mines, Division of Economics and Business. https://ideas.repec.org/p/mns/wpaper/wp202003.html.

Bernard, Alain L., Carolyn Fischer, and Alan K. Fox. 2007. "Is There a Rationale for Output-Based Rebating of Environmental Levies?" Resource and Energy Economics 29 (2): 83-101. https://doi.org/10.1016/j.reseneeco.2006.07.001.

Biden, Joe. 2020. "The Biden Plan to Build a Modern, Sustainable Infrastructure and an Equitable Clean Energy Future." Joe Biden for President: Official Campaign Website. 2020. https://joebiden.com/clean-energy/.

Branger, Frédéric, and Philippe Quirion. 2014. "Price Versus Quantities Versus Indexed Quantities.” FEEM Working Paper No. 085.2014. Foundazione Eni Enrico Mattei. https://doi.org/10.2139/ssrn.2511192.

Bunch, David S., David Lloyd Greene, Timothy Lipman, S. Shaheen, C. Knittel, Y. Fan, D. Brownstone, W. McManus, K. G. Duleep, and E. Marteen. 2011. "Potential Design, Implementation, and Benefits of a Feebate Program for New Passenger Vehicles in California.” Institute of Transportation Research Report UCD-ITS-RR-11_01. Project Final Report Prepared for State of California Air Resources Board and the California Environmental Protection Agency. University of California, Davis.

Burtraw, Dallas, and Kristen McCormack. 2017. "Consignment Auctions of Free 
Emissions Allowances." Energy Policy 107 (August): 337-44. https://doi.org/10.1016/j.enpol.2017.04.041.

Burtraw, Dallas, Karen Palmer, and Danny Kahn. 2010. "A Symmetric Safety Valve." Energy Policy 38 (9): 4921-32. https://doi.org/10.1016/j.enpol.2010.03.068.

Caparrós, Alejandro, Richard E. Just, and David Zilberman. 2016. "Dynamic Relative Standards versus Emission Taxes in a Putty-Clay Model." Journal of the Association of Environmental and Resource Economists, January. https://doi.org/10.1086/681599.

Davis, Lucas W., and Christopher R. Knittel. 2018. "Are Fuel Economy Standards Regressive?" Journal of the Association of Environmental and Resource Economists 6 (S1): S37-63. https://doi.org/10.1086/701187.

DeGette, Diana. 2020. "Text - H.R.7516 - 116th Congress (2019-2020): Clean Energy Innovation and Deployment Act of 2020.” Webpage. 2019/2020. July 10, 2020. https://www.congress.gov/bill/116th-congress/house-bill/7516/text.

D'Haultfœuille, Xavier, Pauline Givord, and Xavier Boutin. 2014. "The Environmental Effect of Green Taxation: The Case of the French Bonus/Malus." The Economic Journal 124 (578): F444-80. https://doi.org/10.1111/ecoj.12089.

Dumas, Alexandre, David L. Greene, and André Bourbeau. 2007. "CHAPTER 7 - North American Feebate Analysis Model." In Driving Climate Change, edited by Daniel Sperling and James S. Cannon, 107-27. Burlington: Academic Press. https://doi.org/10.1016/B978-012369495-9/50008-7.

Durrmeyer, Isis. 2018. "Winners and Losers: The Distributional Effects of the French Feebate on the Automobile Market." Monograph. TSE Working Paper. Toulouse: TSE Working Paper. September 2018. http://tse-fr.eu/pub/32928.

Durrmeyer, Isis, and Mario Samano. 2018. "To Rebate or Not to Rebate: Fuel Economy Standards Versus Feebates." The Economic Journal 128 (616): 3076-3116. https://doi.org/10.1111/ecoj.12555.

Ellerman, A. Denny, and Ian Sue Wing. 2003. "Absolute versus Intensity-Based Emission Caps." $\quad$ Climate $\quad$ Policy 3 (sup2): https://doi.org/10.1016/j.clipol.2003.09.013.

Farrell, Alexander, and Daniel Sperling. 2007. "A Low-Carbon Fuel Standard for California, Part 2: Policy Analysis." Institute of Transportation Studies, Working Paper Series. Institute of Transportation Studies, UC Davis. https://ideas.repec.org/p/cdl/itsdav/qt8xv635dc.html.

Fischer, Carolyn. 2003. "Combining Rate-Based and Cap-and-Trade Emissions Policies." Climate Policy 3 (sup2): S89-103. https://doi.org/10.1016/j.clipol.2003.09.015.

Fischer, Carolyn, and Michael Springborn. 2011. "Emissions Targets and the Real Business Cycle: Intensity Targets versus Caps or Taxes." Journal of Environmental Economics and Management 62 (3): 352-66. https://doi.org/10.1016/j.jeem.2011.04.005.

Fishelson, Gideon. 1976. "Emission Control Policies under Uncertainty." Journal of 
Environmental Economics and Management $3 \quad$ (3): 189-97. https://doi.org/10.1016/0095-0696(76)90018-8.

Gillingham, Kenneth. 2013. "The Economics of Fuel Economy Standards versus Feebates." NEPI Working Paper. National Energy Policy Institute. http://www.ourenergypolicy.org/the-economics-of-fuel-economy-standardsversus-feebates/.

Goulder, Lawrence H., Xianling Long, Jieyi Lu, and Richard D. Morgenstern. 2019. “China's Unconventional Nationwide CO2 Emissions Trading System: The WideRanging Impacts of an Implicit Output Subsidy." w26537. National Bureau of Economic Research. https://doi.org/10.3386/w26537.

Goulder, Lawrence H., and Richard D. Morgenstern. 2018. "China's Rate-Based Approach to Reducing $\mathrm{CO}_{2}$ Emissions: Attractions, Limitations, and Alternatives." $A E A$ Papers and Proceedings 108 (May): 458-62. https://doi.org/10.1257/pandp.20181028.

Goulder, Lawrence H., Richard D. Morgenstern, Clayton Munnings, and Jeremy Schreifels. 2017. "China's National Carbon Dioxide Emission Trading System: An Introduction." Economics of Energy \& Environmental Policy 6 (2). https://doi.org/10.5547/2160-5890.6.2.1gou.

Greene, David L. 1990. "CAFE OR PRICE?: An Analysis of the Effects of Federal Fuel Economy Regulations and Gasoline Price on New Car MPG, 1978-89.” The Energy Journal 11 (3): 37-57.

Greene, David L., Philip D. Patterson, Margaret Singh, and Jia Li. 2005. "Feebates, Rebates and Gas-Guzzler Taxes: A Study of Incentives for Increased Fuel Economy." Energy Policy 33 (6): 757-75. https://doi.org/10.1016/j.enpol.2003.10.003.

Greene, William. 2017. Econometric Analysis. 8th edition. New York, NY: Pearson.

Grüll, Georg, and Luca Taschini. 2011. "Cap-and-Trade Properties under Different Hybrid Scheme Designs." Journal of Environmental Economics and Management 61 (1): 107-18. https://doi.org/10.1016/j.jeem.2010.09.001.

Hepburn, Cameron, Karsten Neuhoff, William Acworth, Dallas Burtraw, and Frank Jotzo. 2016. "The Economics of the EU ETS Market Stability Reserve." Journal of Environmental Economics and Management 80 (November): 1-5. https://doi.org/10.1016/j.jeem.2016.09.010.

Hoel, Michael, and Larry Karp. 2002. "Taxes versus Quotas for a Stock Pollutant." Resource and Energy Economics 24 (4): 367-84. https://doi.org/10.1016/S09287655(02)00014-3.

Holland, Stephen P. 2012. "Emissions Taxes versus Intensity Standards: Second-Best Environmental Policies with Incomplete Regulation." Journal of Environmental Economics and Management $63 \quad$ (3): $375-87$. https://doi.org/10.1016/j.jeem.2011.12.002.

Holland, Stephen P., Jonathan E. Hughes, Christopher R. Knittel, and Nathan C. Parker. 2015. "Unintended Consequences of Carbon Policies: Transportation Fuels, Land- 
Use, Emissions, and Innovation." The Energy Journal 36 (3). https://doi.org/10.5547/01956574.36.3.2.

Johnson, Kenneth C. 2006. "Feebates: An Effective Regulatory Instrument for CostConstrained Environmental Policy." Energy Policy 34 (18): 3965-76. https://doi.org/10.1016/j.enpol.2005.10.005.

Jotzo, Frank, and John C. V. Pezzey. 2007a. "Optimal Intensity Targets for Greenhouse Gas Emissions Trading under Uncertainty." Environmental and Resource Economics 38 (2): 259-84. https://doi.org/10.1007/s10640-006-9078-z.

- 2007b. "Optimal Intensity Targets for Greenhouse Gas Emissions Trading under Uncertainty." Environmental and Resource Economics 38 (2): 259-84. https://doi.org/10.1007/s10640-006-9078-z.

Kellogg, Ryan. 2018. "Gasoline Price Uncertainty and the Design of Fuel Economy Standards.” Journal of Public Economics 160 (April): 14-32. https://doi.org/10.1016/j.jpubeco.2018.02.013.

- 2020. "Output and Attribute-Based Carbon Regulation under Uncertainty." Journal of Public Economics $190 \quad$ (October): 104246. https://doi.org/10.1016/j.jpubeco.2020.104246.

Khezr, Peyman, and Ian A. MacKenzie. 2018. "Consignment Auctions." Journal of Environmental Economics and Management 87 (January): 42-51. https://doi.org/10.1016/j.jeem.2017.11.003.

Klier, Thomas, and Joshua Linn. 2011. "Corporate Average Fuel Economy Standards and the Market for New Vehicles." Annual Review of Resource Economics 3 (1): 44562. https://doi.org/10.1146/annurev-resource-083110-120023.

Kolstad, Charles D. 2005. "The Simple Analytics of Greenhouse Gas Emission Intensity Reduction Targets." Energy Policy 33 (17): 2231-36. https://doi.org/10.1016/j.enpol.2004.05.001.

Konishi, Yoshifumi, and Meng Zhao. 2017. "Can Green Car Taxes Restore Efficiency? Evidence from the Japanese New Car Market." Journal of the Association of Environmental and Resource Economists 4 (1): 51-87. https://doi.org/10.1086/689701.

Leard, Benjamin, and Virginia McConnell. 2017. "New Markets for Credit Trading Under U.S. Automobile Greenhouse Gas and Fuel Economy Standards." Review of Environmental Economics and Policy $11 \quad$ (2): 207-26. https://doi.org/10.1093/reep/rex010.

Lemoine, Derek. 2017. "Escape from Third-Best: Rating Emissions for Intensity Standards." Environmental and Resource Economics 67 (4): 789-821. https://doi.org/10.1007/s10640-016-0006-6.

Marschinski, Robert, and Ottmar Edenhofer. 2010a. "Revisiting the Case for Intensity Targets: Better Incentives and Less Uncertainty for Developing Countries." Energy Policy, Special Section on Carbon Emissions and Carbon Management in Cities with Regular Papers, 38 (9): 5048-58. https://doi.org/10.1016/j.enpol.2010.04.033. 
— 2010b. "Revisiting the Case for Intensity Targets: Better Incentives and Less Uncertainty for Developing Countries." Energy Policy, Special Section on Carbon Emissions and Carbon Management in Cities with Regular Papers, 38 (9): 504858. https://doi.org/10.1016/j.enpol.2010.04.033.

Ministry of Ecology and Environment, P. R. China. 2020. Notice on the Issuance of the "Implementation Plan of 2019-2020 National Carbon Emissions Trading Cap Setting and Allowances Allocation (Power Sector)", "The List of Key Entities Covered by the 2019-2020 National Carbon Emissions Trading Allowances Management" and the Launch of Pre-allocation for Power Sector. http://mee.gov.cn/xxgk2018/xxgk/xxgk03/202012/t20201230_815546.html.

Munnings, Clayton, Richard D. Morgenstern, Zhongmin Wang, and Xu Liu. 2016. "Assessing the Design of Three Carbon Trading Pilot Programs in China." Energy Policy 96 (September): 688-99. https://doi.org/10.1016/j.enpol.2016.06.015.

Murray, Brian C., Richard G. Newell, and William A. Pizer. 2009. "Balancing Cost and Emissions Certainty: An Allowance Reserve for Cap-and-Trade." Review of Environmental Economics and Policy, January, ren016. https://doi.org/10.1093/reep/ren016.

Newell, Richard G., and William A. Pizer. 2003. "Regulating Stock Externalities under Uncertainty." Journal of Environmental Economics and Management 45 (2, Supplement): 416-32. https://doi.org/10.1016/S0095-0696(02)00016-5.

- 2008. "Indexed Regulation." Journal of Environmental Economics and Management 56 (3): 221-33. https://doi.org/10.1016/j.jeem.2008.07.001.

Newell, Richard G., William Pizer, and Jiangfeng Zhang. 2005. "Managing Permit Markets to Stabilize Prices." Environmental \& Resource Economics 31 (2): 133-57. https://doi.org/10.1007/s10640-005-1761-y.

Newell, Richard G., and Kristian Rogers. 2003. "The Market-Based Lead Phasedown." http://www.rff.org/research/publications/market-based-lead-phasedown.

Pizer, William A. 2002. "Combining Price and Quantity Controls to Mitigate Global Climate Change." Journal of Public Economics 85 (3): 409-434.

Pizer, William A., and Brian C. Prest. 2020. "Prices versus Quantities with Policy Updating." Journal of the Association of Environmental and Resource Economists 7 (3): 483-518. https://doi.org/10.1086/707142.

Pizer, William A., and Xiliang Zhang. 2018. "China's New National Carbon Market." AEA Papers and Proceedings 108: 463-67. https://doi.org/10.1257/pandp.20181029.

Quirion, Philippe. 2005. "Does Uncertainty Justify Intensity Emission Caps?" Resource and Energy Economics 27 (4): 343-53. https://doi.org/10.1016/j.reseneeco.2005.05.002.

Roberts, Marc J., and Michael Spence. 1976. "Effluent Charges and Licenses under Uncertainty." Journal of Public Economics 5 (3): 193-208. https://doi.org/10.1016/0047-2727(76)90014-1.

Rubin, Jonathan, Paul N. Leiby, and David L. Greene. 2009. “Tradable Fuel Economy 
Credits: Competition and Oligopoly." Journal of Environmental Economics and Management 58 (3): 315-28. https://doi.org/10.1016/j.jeem.2009.05.002.

Schmalensee, Richard, and Robert N. Stavins. 2017. "The Design of Environmental Markets: What Have We Learned from Experience with Cap and Trade?" Oxford Review of Economic Policy 33 (4): 572-88. https://doi.org/10.1093/oxrep/grx040.

Slater, Huw, Dimitri De Boer, Guoqiang Qian, and Shu Wang. 2020. "2020 China Carbon Pricing Survey." Beijing: China Carbon Forum. http://www.chinacarbon.info/sdm_downloads/2020-china-carbon-pricing-survey/.

Stavins, Robert N. 1996. "Correlated Uncertainty and Policy Instrument Choice." Journal of Environmental Economics and Management 30 (2): 218-32. https://doi.org/10.1006/jeem.1996.0015.

Sue Wing, Ian, A. Denny Ellerman, and Jaemin Song. 2006. “Absolute vs. Intensity Limits for CO2 Emission Control: Performance Under Uncertainty." Technical Report. MIT Joint Program on the Science and Policy of Global Change. http://dspace.mit.edu/handle/1721.1/31204.

Tombe, Trevor, and Jennifer Winter. 2015. "Environmental Policy and Misallocation: The Productivity Effect of Intensity Standards." Journal of Environmental Economics and Management 72 (July): 137-63. https://doi.org/10.1016/j.jeem.2015.06.002.

Webster, Mort, Ian Sue Wing, and Lisa Jakobovits. 2010. "Second-Best Instruments for near-Term Climate Policy: Intensity Targets vs. the Safety Valve." Journal of Environmental Economics and Management 59 (3): 250-59. https://doi.org/10.1016/j.jeem.2010.01.002.

Weitzman, Martin L. 1974. "Prices vs. Quantities." The Review of Economic Studies 41 (4): 477-491.

- 2018. "Prices or Quantities Dominate Banking and Borrowing." Working Paper 24218. National Bureau of Economic Research. https://doi.org/10.3386/w24218.

Wood, Peter John, and Frank Jotzo. 2011. "Price Floors for Emissions Trading." Energy Policy 39 (3): 1746-1753.

Yan, Shiyu, and Gunnar S. Eskeland. 2018. "Greening the Vehicle Fleet: Norway's CO2Differentiated Registration Tax." Journal of Environmental Economics and Management 91 (September): 247-62. https://doi.org/10.1016/j.jeem.2018.08.018.

Yeh, Sonia, Dallas Burtraw, Thomas Sterner, and David Greene. 2020. "Tradable Performance Standards in the Transportation Sector." Working Paper 20-18. Resources for the Future.

Yohe, Gary W. 1978. "Towards a General Comparison of Price Controls and Quantity Controls under Uncertainty." The Review of Economic Studies 45 (2): 229-38. https://doi.org/10.2307/2297337.

Yu, Sha, Jill Horing, Qiang Liu, Robert Dahowski, Casie Davidson, James Edmonds, Bo Liu, et al. 2019. "CCUS in China's Mitigation Strategy: Insights from Integrated Assessment Modeling." International Journal of Greenhouse Gas Control 84 (May): 204-18. https://doi.org/10.1016/j.ijggc.2019.03.004. 
Zhang, Duan, Yihsu Chen, and Makoto Tanaka. 2018. "On the Effectiveness of Tradable Performance-Based Standards." Energy Economics 74 (August): 456-69. https://doi.org/10.1016/j.eneco.2018.06.012.

Zhao, Jinhua. 2018. "Aggregate Emission Intensity Targets: Applications to the Paris Agreement." ADBI Working Paper 813. ADBI. https://doi.org/10.2139/ssrn.3198679. 


\section{Appendix}

\section{A. Comparison and Notions of TPS and Feebate}

We start by showing that feebate and TPS is analog to the prices versus quantities problem in the context of a rate-based cap-and-trade system.

\section{A.1. Tradable performance Standard}

First, considering the tradable performance standard policy. TPS is also known as rate-based regulation, intensity targets, or indexed regulation. It has become an option when emissions are highly related to output levels. Theoretical studies show that it may be preferable to absolute standard if emissions and activities level are highly related (Fischer and Springborn 2011; Jotzo and Pezzey 2007b; Marschinski and Edenhofer 2010b; Sue Wing, Ellerman, and Song 2006).

Under TPS, the policy maker sets an emission limit or target, but it is continuously scaled to some output measure or index, $x$. Therefore, the emission limit or target equals $r_{T} \cdot x$, where $r_{T}$ is the standard / rate / intensity. In practice for a set of firms $i \in\{1, \ldots, I\}$, policy maker allocates allowances based on the firm's output $x_{i}$; that is, a representative firm's allocation is given by $a_{i}=r_{T} \cdot x_{i}$. It is also required to surrender allowances equal to its emissions, $q_{i}$. Therefore, firms will buy $q_{i}-a_{i}$ allowances if $q_{i}>a_{i}$ or sell $a_{i}-$ $q_{i}$ allowances if $q_{i}<a_{i}$, forming a price $p$. In aggregate, $\sum q_{i}=\sum a_{i}=r_{T} \cdot \sum x_{i}$, that is, the average emissions rate is exactly the standard.

\section{A.2. Feebate}

The corresponding price version of TPS is feebates. A typical feebate policy is a system combining a fixed fee levying on emissions and a revenue neutral rebate on output. The instrument has been applied in countries such as France, Denmark, Norway, Canada, etc. for low carbon regulation in transportation sector (Bunch et al. 2011).

For a representative firm, if its production has an emissions rate $r_{i}$ above a standard $r_{T}$, it pays a "fee" equal to $p\left(r_{i}-r_{T}\right)$, where $p$ is a fixed price. When its production has an emissions rate $r_{i}$ below the standard $\bar{r}$, it receives a re-"bate" equal to $p\left(r_{T}-r_{i}\right)$. This is equivalent to a tax on emission $p \cdot r_{i}$ and a subsidy to output equal to $p \cdot r_{T}$. In aggregation, feebate is revenue neutral, that is $\sum p\left(r_{i}-r_{T}\right) x_{i}=p \sum r_{i} x_{i}-$ $p \sum r_{T} x_{i}=0$. It implies that a revenue neutral feebate can achieve emission standard on average.

\section{A.3. Equivalent outcomes under a TPS and feebate}

Under TPS, policy maker sets emissions standard $r_{T}$; markets establish a price $p$ for allowances. Firms have unit production cost functions $c_{i}\left(r_{i}\right)$ in terms of their unit 
emissions $r_{i}=q_{i} / x_{i}$. Moreover, $c_{i}^{\prime}\left(r_{i}\right)<0$ as we require firms to reduce emissions and $c_{i}^{\prime \prime}\left(r_{i}\right)>0$.

With the TPS, firm's unit costs are $c_{i}\left(r_{i}\right)+p \cdot r_{i}-p \cdot r_{T}$ as they buy or sell allowances. Allowances price $p$ adjusts to balance permit supply and demand. Firms choose $r_{i}$ to minimize unit costs, so $c_{i}^{\prime}=-p$.

Given the standard is met on average, the aggregate unit costs are given by $c(\bar{r})$, where $c(r)$ is the unit production cost function averaged across firms, and average emissions rate equals the standard.

Under feebate, instead of setting target and allowing trade, policy maker tax emissions at $p$ and subsidize output at $p \cdot r_{T}$. With feebate tax/subsidy, firm's unit costs are also $c_{i}\left(r_{i}\right)+p \cdot r_{i}-p \cdot r_{T}$. Firms choose $r_{i}$ to minimize unit cots, so $c_{i}^{\prime}=-p$.

Given this corresponds to the TPS outcome at the firm level, feebate have the same outcome in the aggregate: unit costs are given by $c\left(r_{T}\right)$ under assumption that we know what price $p$ corresponds to rate $\bar{r}$.

Note that compared to an emission tax, the feebate generates the same marginal cost, but higher emissions averagely. Compare an emission tax at level $p$ to a feebate that taxes emissions at level $p$ but also subsidizes output at level $p r_{T}$. At the firm level, both will set marginal cost equal to the emission tax or fee. However, the (re)bate part of the feebate lowers unit costs to $c_{i}\left(r_{i}\right)+p r_{i}-p r_{T}$ relative to $c\left(r_{i}\right)+p r_{i}$ under a tax. In the aggregate averaging over all firms, this leads to lower product prices under a feebate compared to a tax equal to the fee, that is, $c\left(r_{T}\right)$ versus $c\left(r_{T}\right)+p r_{T}$. With a non-zero demand elasticity, output (and emissions) will be higher under a feebate compared to a tax equal to the fee. Nevertheless, feebate and TPS would have the same output effect.

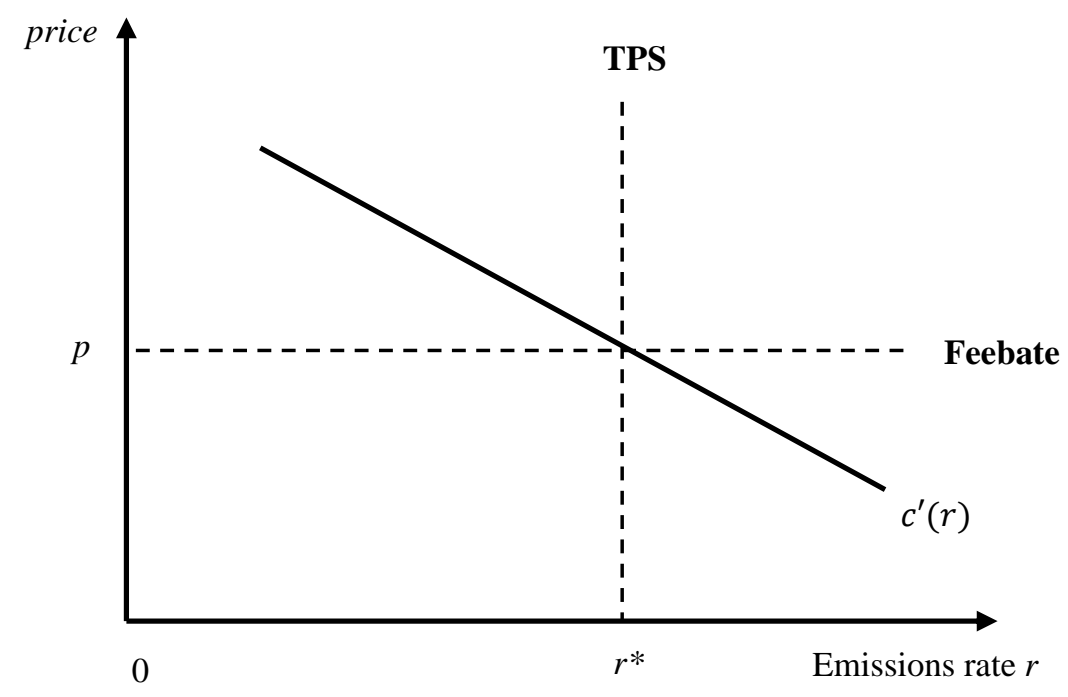

Figure A1. Feebate versus TPS 


\section{B. Calculating comparative advantage}

Write the net benefit function:

$$
\begin{aligned}
N B=b_{0} & +b_{1}\left(r x-r^{*} \bar{x}\right)-\frac{b_{2}}{2}\left(r x-r^{*} \bar{x}\right)^{2} \\
& -c_{0} x-\left(c_{1}+\theta_{c}\right)\left(r-r^{*}\right) x-\frac{c_{2}}{2}\left(r-r^{*}\right)^{2} x
\end{aligned}
$$

Substitute $r=r_{T}$, take expectation, and set $b_{1}=c_{1}$ yields the expected net benefit under TPS at optimal standard:

$$
\begin{aligned}
E\left[N B_{T}\right]=b_{0} & +b_{1}\left(r_{T}-r^{*}\right) \bar{x}-\frac{b_{2}}{2}\left(r_{T}^{2}\left(\bar{x}^{2}+\sigma_{x}^{2}\right)-2 r_{T} r^{*} \bar{x}^{2}+r^{* 2} \bar{x}^{2}\right)-c_{0} \bar{x}-\left(c_{1} \bar{x}\right. \\
& \left.+\sigma_{c x}\right)\left(r_{T}-r^{*}\right)-\frac{c_{2}}{2}\left(r_{T}-r^{*}\right)^{2} \bar{x} \\
= & b_{0}-c_{0} \bar{x}-\left(r_{T}-r^{*}\right) \sigma_{c x}-\left(r_{T}-r^{*}\right)^{2}\left(\frac{b_{2}}{2} \bar{x}^{2}+\frac{c_{2}}{2} \bar{x}\right)-\frac{b_{2}}{2} r_{T}^{2} \sigma_{x}^{2}
\end{aligned}
$$

Now redo for the feebate, subsitituting the response function $r=r_{T}-\frac{\theta_{c}}{c_{2}}$ in the above net benefit expression and taking expectations:

$$
\begin{aligned}
N B_{F}= & b_{0}+b_{1}\left(\left(r_{T}-\frac{\theta_{c}}{c_{2}}\right) x-r^{*} \bar{x}\right)-\frac{b_{2}}{2}\left(\left(r_{T}-\frac{\theta_{c}}{c_{2}}\right) x-r^{*} \bar{x}\right)^{2}-c_{0} x \\
& -\left(c_{1}+\theta_{c}\right)\left(r_{T}-\frac{\theta_{c}}{c_{2}}-r^{*}\right) x-\frac{c_{2}}{2}\left(r_{T}-\frac{\theta_{c}}{c_{2}}-r^{*}\right)^{2} x \\
E\left[N B_{F}\right]=b_{0}+ & b_{1}\left(r_{T}-r^{*}\right) \bar{x}-\frac{b_{1} \sigma_{c x}}{c_{2}} \\
& -\frac{b_{2}}{2}\left(\left(r_{T}^{2}+\frac{\sigma_{c}^{2}}{c_{2}^{2}}\right)\left(\bar{x}^{2}+\sigma_{x}^{2}\right)-2 r_{T} r^{*} \bar{x}^{2}+r^{* 2} \bar{x}^{2}+\frac{\sigma_{c x}^{2}}{c_{2}^{2}}+\frac{2 \sigma_{c x}}{c_{2}} r^{*} \bar{x}\right) \\
& -c_{0} \bar{x}-\left(c_{1} \bar{x}+\sigma_{c x}\right)\left(r_{T}-r^{*}\right)+\frac{\sigma_{c}^{2}}{c_{2}} \bar{x}+\frac{c_{1}}{c_{2}} \sigma_{c x}-\frac{c_{2}}{2}\left(r_{T}-r^{*}\right)^{2} \bar{x}-\frac{c_{2}}{2} \frac{\sigma_{c}^{2}}{c_{2}^{2}} \bar{x} \\
& +\left(r_{T}-r^{*}\right) \sigma_{c x}
\end{aligned}
$$




$$
\begin{aligned}
E\left[N B_{F}\right]=b_{0} & -\frac{\left(r_{T}-r^{*}\right)^{2} \bar{x}}{2}\left(b_{2} \bar{x}+c_{2}\right) \\
& -\frac{b_{2}}{2}\left(r_{T}^{2} \sigma_{x}^{2}+\left(\frac{\sigma_{c}^{2}}{c_{2}^{2}}\right)\left(\bar{x}^{2}+\sigma_{x}^{2}\right)+\frac{\sigma_{c x}^{2}}{c_{2}^{2}}+\frac{2 \sigma_{c x}}{c_{2}} r^{*} \bar{x}\right)-c_{0} \bar{x}+\frac{\sigma_{c}^{2}}{2 c_{2}} \bar{x}
\end{aligned}
$$

Now we can compute the compariative advantage, subtracting $E\left[N B_{T}\right]$ from $E\left[N B_{F}\right]:$

$$
\begin{gathered}
E\left[N B_{F}\right]-E\left[N B_{T}\right] \\
=-\frac{b_{2}}{2}\left(\left(\frac{\sigma_{c}^{2}}{c_{2}^{2}}\right)\left(\bar{x}^{2}+\sigma_{x}^{2}\right)+\frac{\sigma_{c x}^{2}}{c_{2}^{2}}+\frac{2 \sigma_{c x}}{c_{2}} r^{*} \bar{x}\right)+\frac{\sigma_{c}^{2}}{c_{2}} \bar{x}-\frac{\sigma_{c}^{2}}{2 c_{2}} \bar{x} \\
+\left(r_{T}-r^{*}\right) \sigma_{c x} \\
=-\frac{b_{2}}{2}\left(\left(\frac{\sigma_{c}^{2}}{c_{2}^{2}}\right)\left(\bar{x}^{2}+\sigma_{x}^{2}\right)\right)+\frac{c_{2}}{2} \frac{\sigma_{c}^{2}}{c_{2}^{2}} \bar{x}+\left(r_{T}-r^{*}\right) \sigma_{c x}-\frac{b_{2}}{2} \frac{\sigma_{c x}^{2}}{c_{2}^{2}}-b_{2} \frac{\sigma_{c x}}{c_{2}} r^{*} \bar{x} \\
=\frac{\sigma_{c}^{2} \bar{x}}{2 c_{2}^{2}}\left(c_{2}-b_{2} \bar{x}\left(1+v_{x}^{2}\right)\right)-\left(\left(1-\frac{b_{2} \bar{x}+c_{2}}{b_{2} \bar{x}\left(1+v_{x}^{2}\right)+c_{2}}\right)+\frac{b_{2} \bar{x}}{c_{2}}\right) r^{*} \sigma_{c x}-\frac{b_{2}}{2} \frac{\sigma_{c x}^{2}}{c_{2}^{2}} \\
=\frac{\sigma_{c}^{2} \bar{x}}{2 c_{2}^{2}}\left(c_{2}-b_{2} \bar{x}\left(1+v_{x}^{2}\right)\right)-\left(\left(b_{2} \bar{x}+c_{2}\right)\left(1-\frac{c_{2}}{b_{2} \bar{x}\left(1+v_{x}^{2}\right)+c_{2}}\right)\right) \frac{r^{*} \sigma_{c x}}{c_{2}}-\frac{b_{2}}{2} \frac{\sigma_{c x}^{2}}{c_{2}^{2}} \\
=\frac{\sigma_{c}^{2} \bar{x}}{2 c_{2}^{2}}\left(c_{2}-b_{2} \bar{x}\left(1+v_{x}^{2}\right)\right)-\frac{b_{2} \bar{x}\left(1+v_{x}^{2}\right)}{c_{2}} r_{T} \sigma_{c x}-\frac{b_{2}}{2} \frac{\sigma_{c x}^{2}}{c_{2}^{2}}
\end{gathered}
$$

Where $\frac{b_{2} \bar{x}+c_{2}}{b_{2} \bar{x}\left(1+v_{x}^{2}\right)+c_{2}}=\frac{r_{T}}{r^{*}}$.

Or, when there is no correlation,

$$
\Delta_{F-T}=\frac{\sigma_{c}^{2} \bar{x}}{2 c_{2}^{2}}\left(c_{2}-b_{2} \bar{x}\left(1+v_{x}^{2}\right)\right)
$$

And, when there is correlation,

$$
\frac{d \Delta_{F-T}}{d \sigma_{c x}}=-\left(\frac{b_{2} \bar{x}\left(1+v_{x}^{2}\right)}{c_{2}}\right) r_{T}-b_{2} \frac{\sigma_{c x}}{c_{2}^{2}}
$$

We can rewrite this as

$$
\frac{d \Delta_{F-T}}{d \sigma_{c x}}=-\frac{b_{2} \bar{x}\left(1+v_{x}^{2}\right)}{c_{2}}\left(r_{T}+\frac{\rho_{c x} v_{x} \sigma_{c}}{\left(1+v_{x}^{2}\right) c_{2}}\right)
$$


Therefore, for some neighborhood $\left|\sigma_{c x}\right|<\epsilon, \frac{d \Delta_{F-T}}{d \sigma_{c x}}<0$ and positive correlation will favor TPS while negative correlation will favor feebates.

Looking at the second term, it is easy to show $0 \leq v_{x} /\left(1+v_{x}^{2}\right) \leq 1 / 2$ (given $v_{x}>0$ since output $>0$ ). So we can write,

$$
\frac{v_{x} \sigma_{c}}{\left(1+v_{x}^{2}\right) c_{2}}<\frac{\sigma_{c}}{2}
$$

Therefore, a sufficient condition for this derivative to remain negative, regardless of $\sigma_{c x}$, is $2 r_{T}>\sigma_{c} / c_{2}$. That is, the same conclusion about correlation continues to hold so long as the standard deviation of the cost shock, expressed in terms of the standard deviation of the shift in the rate of emissions at a given price (e.g., the "horizontal shock") is less than twice the TPS standard $r T$. When this is violated, specifically,

$$
\frac{\sigma_{c}}{c_{2}}>r_{T} \frac{1+v_{x}^{2}}{v_{x}}
$$

a sufficiently large negative correlation can tilt the comparative advantage towards TPS. Note that a positive correlation always tilts towards TPS.

\section{Cost calculations}

\section{C.1. Calculating the baseline expected TPS cost.}

To compute the expected cost of a TPS relative to a no-policy baseline, we compare the expected TPS cost from the calculation of $E\left[N B_{T}\right]$ in Appendix B and subtract the no policy expected cost, which we define as the expected cost when the price (marginal cost) is fixed at zero. We might imagine that the expected cost ought to be zero when the price is zero, but we have not yet set the parameters to ensure that assumption. In particular, the cost and benefit function have been defined as approximations around a point $q^{*}=r^{*} / \bar{x}$, later assumed to be the benefit maximizing value of $q$ when $x$ is certain.

From Appendix B, we have

$$
E\left[C_{T}\right]=E\left[c\left(r_{T}\right) x\right]=c_{0} \bar{x}+c_{1} \bar{x}\left(r_{T}-r^{*}\right)+\left(r_{T}-r^{*}\right)^{2} \frac{c_{2}}{2} \bar{x}
$$

where we have dropped the benefit terms and terms related to the covariance of $x$ and $\theta_{c}$, which we assume is zero for this exercise.

To compute the expected cost when $p=0$, we first solve the marginal cost equation (4) when marginal cost $=0$, yielding

$$
r=r^{*}-\frac{c_{1}+\theta_{c}}{c_{2}}
$$

We substitute this into the expression for costs yielding: 


$$
\begin{aligned}
C_{p=0}=c\left(r^{*}\right. & \left.-\frac{c_{1}+\theta_{c}}{c_{2}}\right) x \\
& =c_{0} x+\left(c_{1}+\theta_{c}\right)\left(r^{*}-\frac{c_{1}+\theta_{c}}{c_{2}}-r^{*}\right) x+\frac{c_{2}}{2}\left(r^{*}-\frac{c_{1}+\theta_{c}}{c_{2}}-r^{*}\right)^{2} x
\end{aligned}
$$

Simplifying

$$
C_{p=0}=c_{0} x+\left(c_{1}+\theta_{c}\right)\left(-\frac{c_{1}+\theta_{c}}{c_{2}}\right) x+\frac{c_{2}}{2}\left(-\frac{c_{1}+\theta_{c}}{c_{2}}\right)^{2} x
$$

And taking expectations

$$
\begin{gathered}
E\left[C_{p=0}\right]=c_{0} \bar{x}-\frac{c_{1}^{2}+\sigma_{c}^{2}}{c_{2}} \bar{x}+\frac{c_{2}}{2}\left(\frac{c_{1}^{2}+\sigma_{c}^{2}}{c_{2}^{2}} \bar{x}\right) \\
=c_{0} \bar{x}-\frac{c_{1}^{2}+\sigma_{c}^{2}}{2 c_{2}} \bar{x}
\end{gathered}
$$

We now subtract this from the expected TPS cost yielding:

$$
\begin{aligned}
E\left[C_{T}\right]-E\left[C_{p=0}\right] & =c_{0} \bar{x}+c_{1} \bar{x}\left(r_{T}-r^{*}\right)+\left(r_{T}-r^{*}\right)^{2} \frac{c_{2}}{2} \bar{x}-\left(c_{0} \bar{x}-\frac{c_{1}^{2}+\sigma_{c}^{2}}{2 c_{2}} \bar{x}\right) \\
& =\frac{c_{1}^{2}+\sigma_{c}^{2}}{2 c_{2}} \bar{x}+c_{1} \bar{x}\left(r_{T}-r^{*}\right)+\left(r_{T}-r^{*}\right)^{2} \frac{c_{2}}{2} \bar{x}
\end{aligned}
$$

Without loss of generality, we have assumed $-c_{1}$ is the expected price $r=r^{*}$, call this $E\left[p_{r^{*}}\right]$. And from (4), we know that $-c_{2}\left(r_{T}-r^{*}\right)$ is the expected TPS price difference between a TPW with $r=r_{T}$ and a TPS with $r=r^{*}$. Call this $E\left[p_{r_{T}}\right]-E\left[p_{r^{*}}\right]=$ $E\left[\Delta P_{r_{T}-r^{*}}\right]$. Thus we can rewrite

$$
\begin{gathered}
E\left[C_{T}\right]-E\left[C_{p=0}\right]=\frac{\bar{x}}{2 c_{2}}\left(\sigma_{c}^{2}+E\left[p_{r^{*}}\right]^{2}+2 E\left[p_{r^{*}}\right] E\left[\Delta P_{r_{T^{-}-r^{*}}}\right]+E\left[\Delta P_{r_{T^{-}-r^{*}}}\right]^{2}\right) \\
=\frac{\bar{x}}{2 c_{2}}\left(\sigma_{c}^{2}+E\left[p_{r_{T}}\right]^{2}\right)
\end{gathered}
$$

\section{C.2. Calculating the expected variance of our truncated normal distribution} coupled with a discrete value at the truncation point

When prices are low relative to the variation in cost shocks, a TPS may not bind. That is, a favorable cost shock will reduce compliance costs to the point that the marginal 
cost with our linear schedule appears less than zero at the TPS rate $r_{T}$. This is illustrated in Figure 9. In reality, the price will be zero.

One way to address this without affecting our results is to change the assumed distribution of $\theta_{c}$. In particular, if $\theta_{\max }=-c_{1}-c_{2}\left(r_{T}-r^{*}\right)=E[p]$ then we can define a new error,

$$
\theta_{c}^{\prime} \sim\left\{\begin{array}{lll}
\operatorname{TN}\left(0, \sigma_{c},-\infty, \theta_{\max }\right) & \text { with probability } & 1-\pi \\
\theta_{\max } & \text { with probability } & \pi
\end{array}\right.
$$

where $\mathrm{TN}(\mu, \sigma, b)$ is a upper-tail truncated normal distribution with mean $\mu$, standard deviation $\sigma$, and maximum $b$. In particular, we choose $\pi$ such that $E\left[\theta_{c}^{\prime}\right]=0$. In this way, all of our previous results continue to hold, except that $\sigma_{c}^{2}$ needs to be replaced with $E\left[\left(\theta_{c}^{\prime}\right)^{2}\right]$ (in Equation (14), for example). Greene (2017) derives the mean and variance of the one-sided truncated normal to be

And

$$
\mu-\sigma \frac{\phi(\beta)}{\Phi(\beta)}
$$

$$
\sigma^{2}\left(1-\beta \frac{\phi(\beta)}{\Phi(\beta)}-\left(\frac{\phi(\beta)}{\Phi(\beta)}\right)^{2}\right)
$$

Where $\beta=(b-\mu) / \sigma=\theta_{\max } / \sigma_{c}=E[p] / \sigma_{c}$, e.g., the number of standard deviations $\sigma$ between the expected price and zero, and $\phi(z)$ and $\Phi(z)$ and the standard normal PDF and CDF respectively. Once we know $\beta$ in our applications, it is easy show that choosing

$$
\pi=\frac{\sigma_{c} \frac{\phi(\beta)}{\Phi(\beta)}}{\theta_{\max }+\sigma_{c} \frac{\phi(\beta)}{\Phi(\beta)}}=\frac{\frac{\phi(\beta)}{\Phi(\beta)}}{\beta+\frac{\phi(\beta)}{\Phi(\beta)}}
$$

In other words, as $\beta$ becomes large $(>2), \pi$ will be negligible as $\phi \approx 0.05$ and $\Phi \approx 1$. If $\beta$ were 0.5 , however, $\pi \approx 0.5$. Letting VTN be the variance of the truncated normal distribution given above, with $\sigma=\sigma_{c}$ and $\beta=E[p] / \sigma_{c}$, we have

$$
\begin{gathered}
E\left[\left(\theta_{c}^{\prime}\right)^{2}\right]=\pi \theta_{\text {max }}^{2}+(1-\pi) \sigma_{c}^{2}\left(\left(\frac{\phi(\beta)}{\Phi(\beta)}\right)^{2}+1-\beta \frac{\phi(\beta)}{\Phi(\beta)}-\left(\frac{\phi(\beta)}{\Phi(\beta)}\right)^{2}\right) \\
=\pi \theta_{\text {max }}^{2}+(1-\pi) \sigma_{c}^{2}\left(1-\beta \frac{\phi(\beta)}{\Phi(\beta)}\right)
\end{gathered}
$$

We use this expression to make calculations of $E\left[\left(\theta_{c}^{\prime}\right)^{2}\right]$ in Table 1 and Table 2. 


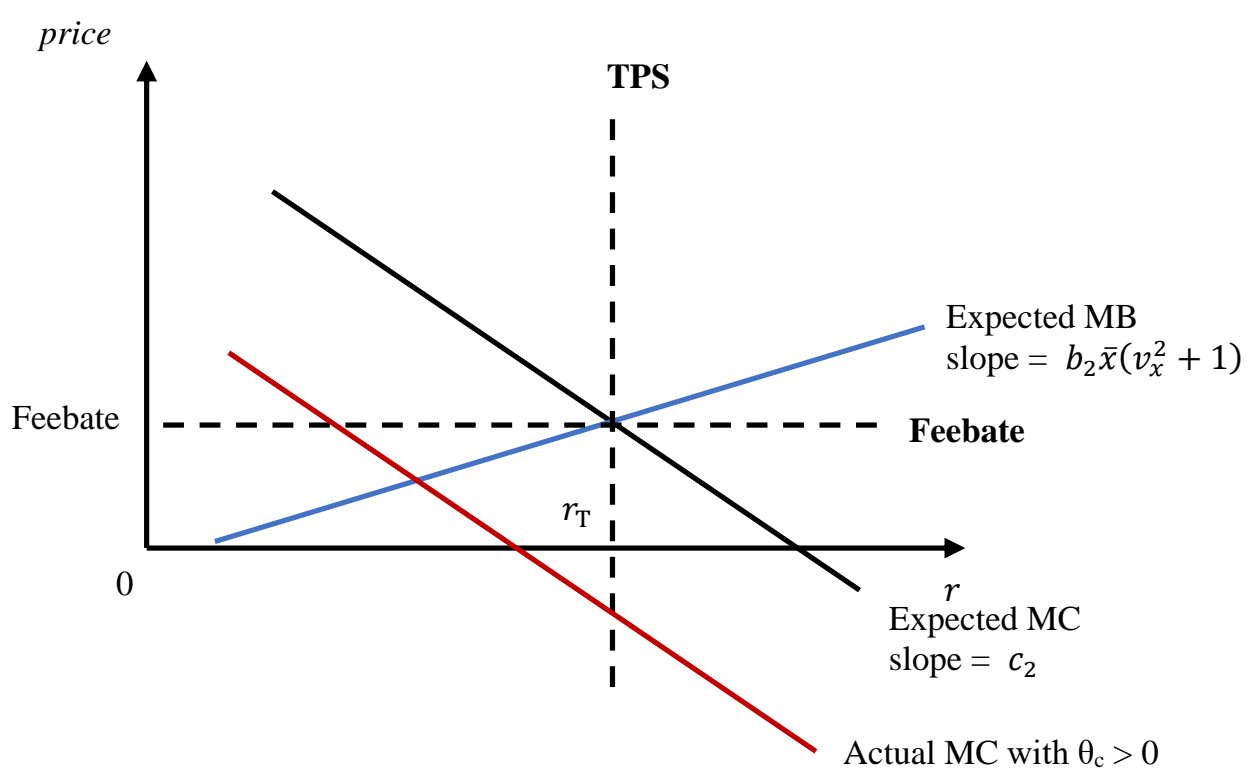

Figure 9. Favorable cost shock when expected prices are low.

\section{Calculating full and partial consignment auctions}

\section{D.1. Full consignment auctions}

With full consignment, a firm will be allocated allowances for consignment auction according to the rate $r_{T}$. The firm's allocaiton is $r_{T} x_{i}$ and emissions (obligations) are $r_{i} x_{i}$. Introduce a floor price $p_{\min }$ in the acution. Therefore, the total revenue of consignment auction would be:

$$
\Gamma=\left\{\begin{array}{lll}
\Sigma r_{T} x_{i} p, & \text { if } & p>p_{\text {min }} \\
\alpha_{\text {full }} r_{T} \Sigma x_{i} p_{\text {min }} . & \text { if } & p=p_{\text {min }}
\end{array}\right.
$$

Each firm's revenue would be:

$$
\gamma=\left\{\begin{array}{lll}
r_{T} x_{i} p, & \text { if } & p>p_{\text {min }} \\
\alpha_{\text {full }} r_{T} x_{i} p_{\text {min }}, & \text { if } & p=p_{\text {min }}
\end{array}\right.
$$

They are output shares of the total revenue no matter whether market hits the minimum price.

Firms can buy allowances in the same auction with the clearing price for compliance. The total expenditure of all regulated firms would be: 


$$
\Lambda=\left\{\begin{array}{lll}
\Sigma r_{i} x_{i} p, & \text { if } & p>p_{\text {min }} \\
\Sigma r_{i} x_{i} p_{\text {min }}, & \text { if } & p=p_{\text {min }}
\end{array}\right.
$$

And because of the revenue neutral nature of consignment auctions, the total auction revenue equals the total expenditure $\Gamma=\Lambda$. It is easy to show that:

(1) If the clearing price is greater than the floor, the ex post average intensity among firms equals the target rate:

$$
\bar{r}=r_{T} .
$$

(2) If the market hits the floor, the minimum price maintained, while only $\alpha_{f u l l}$ fraction of allowances sold at auction, and

$$
\alpha_{f u l l}=\frac{\bar{r}}{r_{T}},
$$

which is below 1 (and greater than 0 ) because in this case the ex post average intensity is smaller than the original standard due to demand shocks.

Therefore, each regulated firm's net expenditures with full consignment are:

$$
\varepsilon=\left\{\begin{array}{lll}
\left(r_{i}-\bar{r}\right) x_{i} p, & \text { if } & p>p_{\text {min }} \\
\left(r_{i}-\bar{r}\right) x_{i} p_{\text {min }}, & \text { if } & p=p_{\text {min }}
\end{array}\right.
$$

\section{D.2. Partial consignment auctions}

With partial consignment, a firm will be immediately allocated some free allowances according to its output and a standard lower than the performance standard $r_{T, \text { min }}$. The rest part of free allowances which equals to the difference between the two standard and the firms' output $\left(r_{T}-r_{T, \min }\right) x_{i}$, are then allocated for consignment auction.

Therefore, the total revenue of consignment auction with a minimum price would be:

$$
\Gamma=\left\{\begin{array}{lll}
\Sigma\left(r_{T}-r_{T, \min }\right) x_{i} p, & \text { if } & p>p_{\text {min }} \\
\Sigma\left(r_{T}-r_{T, \min }\right) x_{i} p_{\text {min }} \alpha_{\text {part }} . & \text { if } & p=p_{\text {min }}
\end{array}\right.
$$

Each firm's revenue would be:

$$
\gamma=\left\{\begin{array}{lll}
\left(r_{T}-r_{T, \text { min }}\right) x_{i} p, & \text { if } & p>p_{\text {min }} \\
\left(r_{T}-r_{T, \text { min }}\right) x_{i} p_{\text {min }} \alpha_{\text {part }}, & \text { if } & p=p_{\text {min }}
\end{array}\right.
$$

which are also the output share of the total revenue no matter whether market hits the minimum price. 
The total expenditure of firms to fulfill their obligation is:

$$
\Lambda=\left\{\begin{array}{lll}
\Sigma\left(r_{i}-r_{T, \text { min }}\right) x_{i} p, & \text { if } & p>p_{\text {min }} \\
\Sigma\left(r_{i}-r_{T, \text { min }}\right) x_{i} p_{\text {min }}, & \text { if } & p=p_{\text {min }}
\end{array}\right.
$$

Given the revenue neutral condition, $\Gamma=\Lambda$, it is also easily shown that:

(1) If the clearing price is higher than the price floor, the rate holds:

$$
\bar{r}=r_{T}, \quad \text { if } \quad p>p_{\min }
$$

(2) If the market hits the price floor, the minimum price holds, and the fraction of allowances that would be sold is:

$$
\alpha_{\text {part }}=\frac{\bar{r}-r_{T, \min }}{r_{T}-r_{T, \min }}, \text { if } p=p_{\text {min }}
$$

(3) It is obvious that $\alpha_{\text {part }}$ would only be greater than 0 if $\bar{r}>r_{T, \min }$. That is, if the demand is too low, the mechanism maintains the lower rate $r_{T, \min }$ instead of the price floor.

Each regulated firm's net expenditures with partial consignment are the same with that with full consignment:

$$
\varepsilon=\left\{\begin{array}{lll}
\left(r_{i}-\bar{r}\right) x_{i} p, & \text { if } & p>p_{\text {min }} \\
\left(r_{i}-\bar{r}\right) x_{i} p_{\text {min }}, & \text { if } & p=p_{\text {min }}
\end{array}\right.
$$

